\title{
A CHINA NA AMÉRICA DO SUL E AS IMPLICAÇÕES GEOPOLÍTICAS DO CONSENSO DO PACÍFICO
}

\author{
Javier Vadell $^{1}$
}

RESUMO

O artigo analisa as implicações políticas da crescente interdependência econômica entre a República Popular da China (RPC) e os países da América do Sul. Apresentam-se dados sobre o comércio e investimento da RPC na sub-região e destacam-se os avanços diplomáticos em matéria de cooperação bilateral no decorrer do século XXI. Parte-se da questão de se estaríamos perante um padrão de relacionamento que poderia constituir uma renovada relação de cooperação SulSul ou, pelo contrário, um novo tipo de relacionamento Norte-Sul. A nossa hipótese é que a evolução e a dinâmica desse relacionamento se assemelham mais a um sistema ou padrão Norte-Sul com características bem particulares. Denominamos esse padrão de relacionamento de Consenso do Pacífico (CP). Embora no curto prazo o fator China estimule o crescimento da sub-região, o CP traz implicações diferenciadas para o desenvolvimento dos países que possuem um setor industrial importante - ex. Brasil e Argentina - e aqueles que não o possuem - ex. Chile e Peru, que inclusive assinaram tratados de livre comércio com o gigante asiático. O artigo conclui com algumas considerações a respeito das conseqüências que o CP tem no processo de integração sul-americana.

PALAVRAS-CHAVE: China; América do Sul; integração; Consenso do Pacífico.

\section{INTRODUÇÃO}

América do Sul experimentou, de 2002 a 2010, um crescimento econômico destacável, após os magros resultados das reformas econômicas liberalizantes implementadas nos países da América Latina, com maior ou menor radicalidade, na década de 1990. O Consenso de Washington (CW), como modelo e programa político de desenvolvimento para a América Latina, fracassou em três pontos fundamentais: em primeiro lugar, nos índices de crescimento e nos indicadores sociais, consolidando ainda mais a desigualdade social historicamente presente na região. Em segundo lugar, o fracasso faz-se evidente no colapso institucional e fiscal dos estados dos países da região. Aplicando a receita privatista e de abertura comercial e financeira unilateral, os países endividados da região e com economias débeis ficaram sem respostas perante a crise de finais da década de 1990, com ainda poucas opções políticas e dependentes de organizações financeiras internacionais - Fundo Monetário Internacional (FMI) e Banco Mundial - para

1 O autor agradece a colaboração dos alunos de graduação do Curso de Relações Internacionais da Pontifícia Universidade Católica de Minas Gerais (PUC-MG): Camila Mendonça, Daniele Cardoso e Hugo Markiewicz Fernandes. obter empréstimos. Em terceiro lugar, o fracasso do CW manifesta-se também no plano ideacional. Sustentado pela ideologia liberal (MORAES, 2001; VADELL, 2002; HARVEY, 2008), esse modelo de desenvolvimento para a América Latina partia do pressuposto que, aplicando o receituário dos dez pontos que Williamson destacou no seu famoso artigo, os países da América Latina iriam finalmente não só seguir a trilha correta do capitalismo vitorioso da Guerra Fria, mas também achar o atalho que os conduziria para o primeiro mundo de uma maneira mais rápida, embora em certos casos dolorosa.

Esse modelo mostrou-se não só pífio como utópico. O ano 2001 marca, talvez, o momento simbólico de ruptura desse processo na América Latina. Em termos mais precisos, 2001 é um ano em que aconteceram algumas mudanças políticas e econômicas no plano global de grande destaque: a crise econômica de 2001 na região é resultado de uma crise do capitalismo global de finais da década de 1990 atingindo de maneira dramática o México, o sudeste asiático, a Turquia e a Rússia. Na região, o caso paradigmático foi a crise Argentina de dezembro de 2001, país que seguiu a receita neoliberal de maneira radical. No ano de 2001 também aconteceram os atentados terroristas do grupo $\mathrm{Al}$ Qaeda nos Estados Unidos da América (EUA), fato que 
reconfigurou a política de segurança da superpotência e, também, a sua política econômica baseada nos juros baixos ( $1 \%$ ao ano) e de estímulo ao gasto, que se acelerou ainda mais após as intervenções armadas no Afeganistão e Iraque. Em 2001 acontece o ingresso da República Popular da China (RPC) na Organização Mundial do Comércio (OMC) e sua crescente presença no comércio internacional. Assim, se, por um lado, os EUA começam a priorizar geopoliticamente a região de Oriente Médio e a Rússia e, geoeconomicamente, as relações comerciais e financeiras com a China e o Sudeste Asiático, é verdade que, para a América Latina - mas principalmente para a América do Sul - surge, em plena crise econômica, uma nova opção no horizonte: a crescente presença da RPC no comércio internacional como compradora de recursos naturais e energéticos, cujos preços, por razões de maior demanda, especulativas e geopolíticas, experimentaram substantivas elevações pelo menos até a crise de 2008.

A RPC, potência mundial e ator fundamental das novas mudanças geopolíticas e geoestratégicas no século XXI, tem se tornado um motor econômico global, crescendo a uma taxa de mais de 9,5\%, em média, nas últimas duas décadas (ver Gráfico 1). Com sua imensa população, seu poder militar e seu arsenal nuclear, sua crescente necessidade de recursos energéticos e de diversas commodities, produto de seu elevado crescimento econômico, que está transformando rapidamente sua estrutura social, a China tem criado as condições para sua expansão global, mudando o cenário geopolítico e geoeconômico. Assim, a clássica visão da interdependência entre o ator estatal China com as potências Ocidentais, que outrora poderia ser considerada de "vertical", ou Norte-Sul, está sendo questionada nos dias de hoje - p. ex., a relação RPC-EUA, RPC-União Européia e RPC-Rússia - devido ao peso que a China tem nas questões de segurança global e, sobretudo, na economia internacional. Assim, levando em consideração essa premissa, fica claro o status da RPC como uma potência global e não como mais uma "potência emergente”.

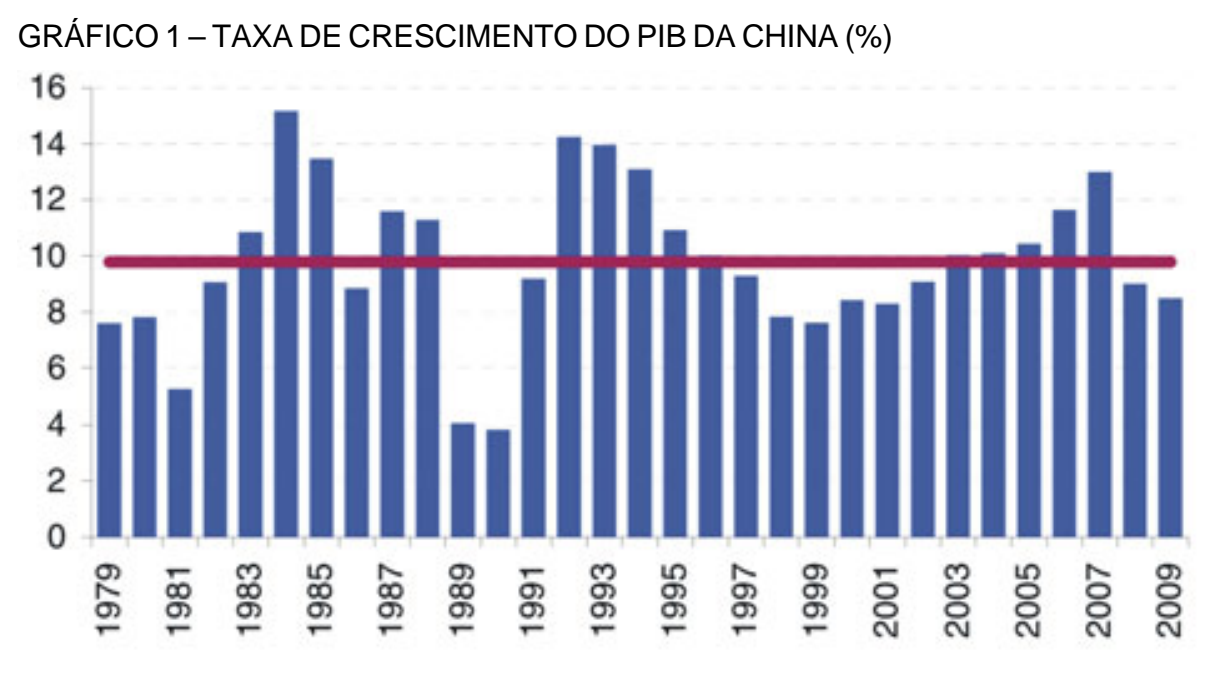

Taxa de crescimento

Média anual: $9,8 \%$

FONTE: Bárcena e Rosales (2010) a partir dos dados do National Bureau of Statistics of China.

De tal modo, na geoeconomia global, o crescimento da China e sua expansão valorizaram os produtos produzidos na periferia, fato que aumentou o poder de barganha dos países da América Latina e da África na divisão internacional do trabalho. Por outro lado, na geopolítica internacional, a ascensão da RPC tem criado novas fontes de conflito com os poderes centrais e, poderíamos adicionar, com algumas potências regionais.
A dinâmica conflito-cooperação também está ligada ao abastecimento dos recursos naturais e energéticos, que provocou a elevação dos preços a partir de 2002 e da crescente necessidade desses recursos por parte da China para sustentar seu espetacular crescimento (VADELL, 2007; 2010). "Isso tem provocado respostas por parte da China no sentido de conformar novas alianças com o intuito de aproximar o sistema internacio- 
nal para uma ordem multipolar”. Dessa maneira, parte-se da premissa de que a RPC está modificando a balança de poder entre o centro e a periferia gerando um conjunto de desdobramentos que, por um lado, podem provocar novas formas de cooperação e novas configurações geoeconômicas, mas também provocar novas fontes de tensões e conflitos geopolíticos (idem).

Por essa mesma razão, questionamos neste trabalho o tipo de relacionamento que para o olhar menos cauto apresenta-se como uma clássica interdependência ou cooperação Sul-Sul, como é o caso da cada vez mais profícua relação entre a RPC e os países da América Latina e da África. Nesse sentido, se considerarmos que a RPC projeta-se como potência econômica e política global no século XXI, devemos analisar, mais detidamente, o tipo e padrão de relacionamento que essa potência está desenvolvendo com os países da América Latina e a África no novo quadro geopolítico global. Nessa direção, a nossa proposta pretende focar a crescente relação entre a China com os países da América do Sul, a fim de explorar as implicações políticas regionais derivadas desse estreitamento de vínculos econômicos e as conseqüências para a política externa do Brasil na região.

É importante mencionar que a crescente presença da RPC na América Latina tem três desdobramentos políticos de extrema importância: (i) a mudança da relação dos EUA com a região a partir da maior presença da China, configurando uma particular relação triangular de relevância crescente na geopolítica hemisférica (TOKATLIAN,2008); (ii) a importância da RPC no impulso do crescimento econômico da região a partir de 2001-2002, fator fundamental para entender a recuperação econômica de muitos países da América do Sul após o fracasso das políticas econômicas neoliberais e (iii) o papel do Brasil, como líder regional e ator diretamente ligado aos desdobramentos positivos e negativos do relacionamento crescente com a RPC. O fato de a China passar a ser o principal parceiro comercial do Brasil em 2009, tirando os EUA dessa posição, assinala um novo cenário geoeconômico, que parece acentuar-se após a crise econômica de 2008.

Contudo, por motivo de espaço, nosso artigo centra-se nos pontos ii e iii e as perguntas centrais são: quais implicações políticas sub-regionais podem-se apontar a partir da crescente interdependência econômica entre a RPC e os países da América do Sul? Estar-se-ia criando um padrão de relacionamento que poderia constituir uma renovada relação de cooperação Sul-Sul ou, pelo contrário, um novo tipo de relacionamento Norte-Sul? Quais implicações essa relação traz para o Brasil e para a integração na América do Sul? Nosso recorte histórico vai de 2001 a 2008, quando aconteceu a crise financeira global que impactou de maneira dramática as economias dos países desenvolvidos do Ocidente.

O trabalho está dividido em cinco seções além da introdução. Na segunda parte, abordamos a questão mais geral da relação entre a RPC e a América Latina, apontando as principais motivações chinesas dessa interdependência crescente. A terceira parte do artigo foca especificamente as relações comerciais e de investimento entre a RPC e os principais países da América do Sul, mediadas por uma ativa diplomacia que se consolida no decorrer da primeira década do século XXI. Na quarta parte do trabalho, pretendemos definir o conceito: Consenso do Pacífico (CP), com o objetivo de caracterizar esse crescente relacionamento de bases fundamentalmente, mas não exclusivamente, comerciais, que apresenta mais traços de uma relação Norte-Sul, do que uma cooperação Sul-Sul, embora com características peculiares. Finalmente, nas conclusões, abordamos alguns pontos em relação às implicações que o CP teria, no médio prazo, no processo de integração sul-americana.

\section{A ESTRATÉGIA POLÍTICA DA RPC NO SEU PROCESSO DE EXPANSÃO ECONÔ- MICA GLOBAL: AS IMPLICAÇÕES PARA A AMÉRICA DO SUL NO SÉCULO XXI}

As relações econômicas entre a China e os países latino-americanos começam a intensificarse efetivamente a partir de 2001 e 2002 (VADELL, 2007). Esses progressos mostraram-se mais consistentes em 2004 e 2005, quando o Presidente Hu Jintao e o Vice-Presidente Zeng Qinhong visitaram vários países da América do Sul e assinaram dezenas de acordos comerciais, de investimentos e de cooperação em várias áreas. Desde então, as autoridades chinesas em muitas oportunidades não se cansam de afirmar que a prioridade do relacionamento com todos os países da América Latina é estritamente de caráter econômico. Os dados que apresentaremos confirmam 
essa tendência - ainda que não devamos descartar as implicações e fins políticos sempre presentes nas relações internacionais.

Se olharmos um pouco a história do século $\mathrm{XX}$, e especificamente durante a Guerra Fria, observaremos que o relacionamento da RPC com os países da América Latina esteve marcado pelo pragmatismo, independentemente do tinte político dos governos da região. No Chile, o governo democrático de Salvador Allende estreitou vínculos e foi o primeiro país latino-americano a reconhecer a RPC. Posteriormente, a ditadura de Pinochet continuou a estreitar os laços com a RPC, especialmente quando esse governo começou a ficar cada vez mais isolado internacionalmente. $\mathrm{O}$ mesmo podemos dizer da ditadura argentina da década de 1970. Argentina e a China assinaram acordos de comércio e cooperação em 1978 e 1980 e o Presidente de facto, Jorge R. Videla, foi o primeiro Presidente argentino que visitou a RPC. O compromisso político no âmbito da Organização das Nações Unidas era o seguinte: a China reconheceria e apoiaria as reclamações argentinas de soberania nas ilhas do Atlântico Sul e, em troca, a Argentina reconheceria oficialmente a RPC e Taiwan como província parte deste país.

De fato, as lideranças de extrema direita e as forças armadas da América Latina não viam a China como um problema de segurança no contexto da Guerra Fria. As relações diplomáticas e comerciais foram estimuladas entre os países da região por governos ditatoriais e de direita (DOMÍNGUEZ, et al., 2006, p.6). O alto grau de pragmatismo do relacionamento consolidou-se durante o período das reformas na China, na década de 1980. As lideranças chinesas, por exemplo, chegaram a denunciar enfaticamente que o grupo guerrilheiro peruano Sendero Luminoso, de inspiração maoísta, era “revisionista e contrarrevolucionário" (ibidem).

A característica pragmática do mútuo relacionamento atravessa o século XX e aprofunda-se no século XXI, ainda que em um cenário de política internacional muito diferente, assim como o contexto da economia global e o papel da RPC nessa conjuntura. A variável comercial hoje é muito mais relevante e crucial no novo estreitamento de vínculos, embora a questão "Taiwan” apareça recorrentemente, mas não ao ponto de quebrar o pragmatismo. Dessa maneira, consideramos importante apontar para quatro objetivos fundamentais que a RPC, no processo de estreitamento das relações com a América Latina e com os países da África, persegue.

Em primeiro lugar, a RPC necessita de recursos naturais e commodities. Ao passo que a China manteve um crescimento médio de mais de $9 \%$ nos últimos 30 anos, esse país passou a depender cada vez mais de recursos energéticos e outras commodities. Os países dos continentes americanos e da África, ricos em recursos, apresentaram-se como fornecedores quase "naturais" para o gigante asiático, estimulando o comércio que experimentou um crescimento surpreendente a partir do ano 2001.

Em segundo lugar, a China empreendeu uma cruzada diplomática para o reconhecimento da RPC, em detrimento de Taiwan, já que muitos países da América Latina e da África reconhecem Taipei e não Pequim ${ }^{2}$. O isolamento de Taiwan é um objetivo da RPC que se manifesta em sua política global. Contudo, o fato de um país não reconhecer oficialmente a RPC não implica que não se estabeleçam relações comerciais. Por trás desse jogo de reconhecimento existe toda uma "diplomacia do dólar", investimentos em áreas de infraestrutura e social e aumento do comércio que envolve uma complexa trama de relações entre as elites dos países em desenvolvimento com os investidores chineses - de Taiwan ou da RPC (TAYLOR, 2006; 2009; ALDEN, 2007; ELLIS, 2009).

Em terceiro lugar, outro ponto importante que estimula a expansão da RPC para o 'Sul' é o apoio nos foros e instituições multilaterais. O bom relacionamento diplomático com os países do Sul tem como finalidade ganhar apoio - e votos - nas organizações internacionais e em outros foros diplomáticos, mas, principalmente, na Assembléia Geral das Nações Unidas, em que o voto de cada Estado tem o mesmo peso (ALDEN, 2007; ELLIS, 2009).

Finalmente, a América Latina apresenta-se como um potencial grande mercado consumidor de produtos chineses. Após a crise econômica de 2008, os EUA e a União Européia sofreram uma contração econômica importante, de modo que ficou mais patente a necessidade de a RPC diversificar as suas exportações para evitar uma diminuição do cresci-

2 Atualmente, são 13 os países que não reconhecem a RPC na América Latina: Paraguai, na América do Sul; Panamá, Nicarágua, El Salvador, Honduras, Guatemala e Belize, na América Central; República Dominicana, Haiti, St. Kitts e Nevis, St. Vincent e as Grenadinas e St. Lucia, no Caribe. 
mento, como expressou o Professor Jiang Shixue: "A expansão para os mercados da América Latina tem sido parte dos objetivos da China de reduzir a sua dependência em relação aos Estados Unidos, Japão e a Europa” (JIANG, 2008, P. 46). Os desdobramentos dessa política manteve aquecido o comércio entre RPC e a América Latina, agora com uma entrada cada vez mais expressiva de produtos manufaturados chineses, o que derivou em dois problemas que vamos abordar posteriormente: em primeiro lugar, afetou os setores industriais, principalmente de países como o Brasil, a Argentina e o México; em segundo lugar, aumentou o deficit comercial de muitos países da região em relação à RPC, ainda que em graus diferenciados. Segundo Gallagher e Porzecanski (2010), o caso mais preocupante talvez seja o México.

\section{A ENTRADA DO DRAGÃO, A RECUPERA-} ÇÃO ECONÔMICA E AS IMPLICAÇÕES PARAAAMÉRICADO SUL

\section{III.1. A explosão do comércio}

O substantivo aumento do comércio entre os países da América do Sul e a RPC a partir de 2001 deve ser interpretado no contexto das mudanças da economia global e do aumento do comércio da
China com o mundo. Na realidade, em maior ou menor medida, a maior parte dos países da América Latina beneficiaram-se com o crescimento do comércio bilateral com a China a partir de 2002. Várias pesquisas e publicações recentes têm como preocupação central entender quais os desdobramentos políticos e econômicos do crescente estreitamento comercial - e, em menor medida, de investimentos - entre a China e a América Latina (BLÁZQUEZ-LIDOY et alii, 2006; ELLIS, 2006; ARSON et alii, 2008; GALLAGHER \& PORZECANSKI, 2009; 2010; SANTISO, 2009). No entanto, não há estudos específicos das conseqüências para a América do Sul, como espaço geo-econômico diferenciado do resto da América Latina. Em outros termos, levando em consideração a explosão comercial da China com a América Latina, o intercâmbio entre os países da subregião de México e América Central mostra um cenário e perspectivas diferentes em relação ao intercâmbio RPC-América do Sul, em dois sentidos. Em primeiro lugar, como mostram os gráfi$\cos 3$ e 4, o comércio da China com a América do Sul apresenta-se muito mais equilibrado do que o comércio entre a China e México-América Central, que têm um deficit na balança comercial com a China muito preocupante.

\section{GRÁFICO 2 - EXPORTAÇÕES, IMPORTAÇÕES E SALDO COMERCIAL DAAMÉRICA LATINA E O CARIBE} COM A RPC (EM MILHÕES DE US\$)

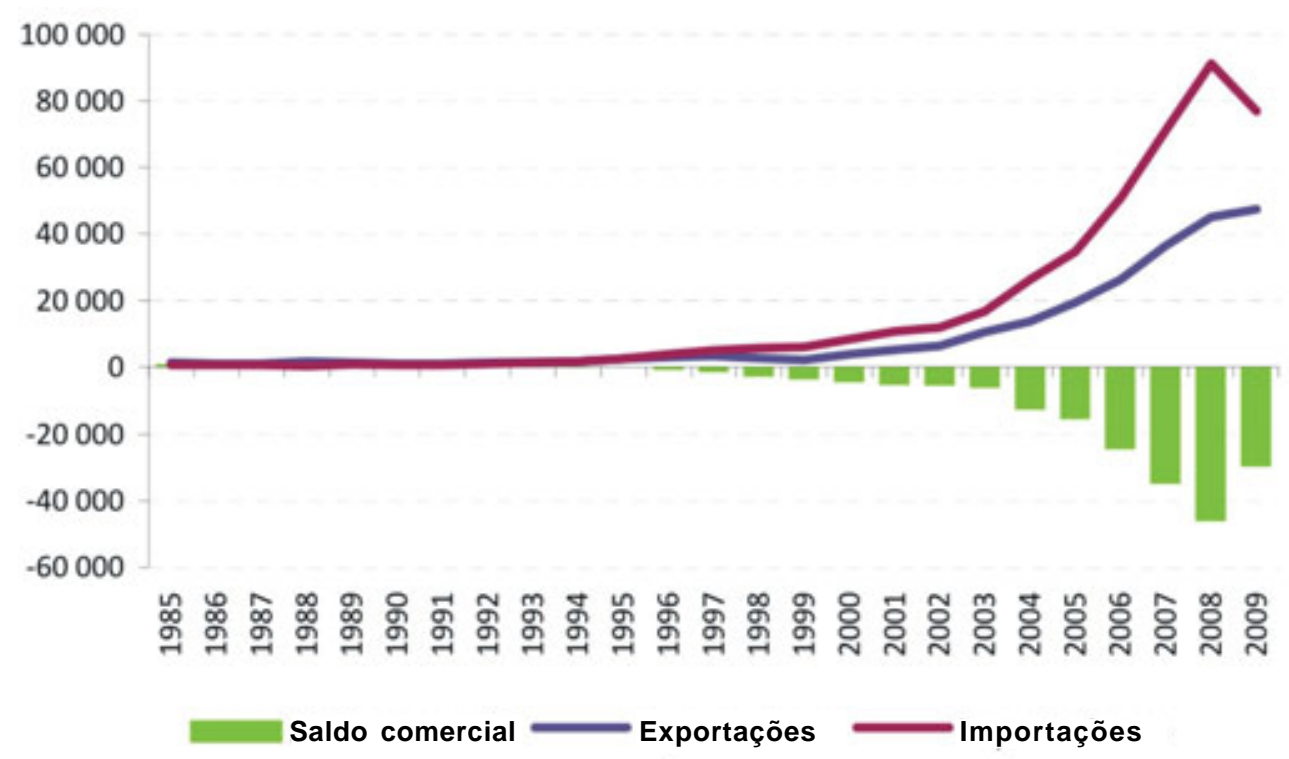

FONTE: Bárcena e Rosales (2010), a partir dos dados da Comisión Económica para a América Latina e o Caribe (Cepal). 
GRÁFICO 3 - EXPORTAÇÕES, IMPORTAÇÕES E SALDO COMERCIAL DAAMÉRICADO SUL COM ARPC (EM MILHÕES DE US\$)

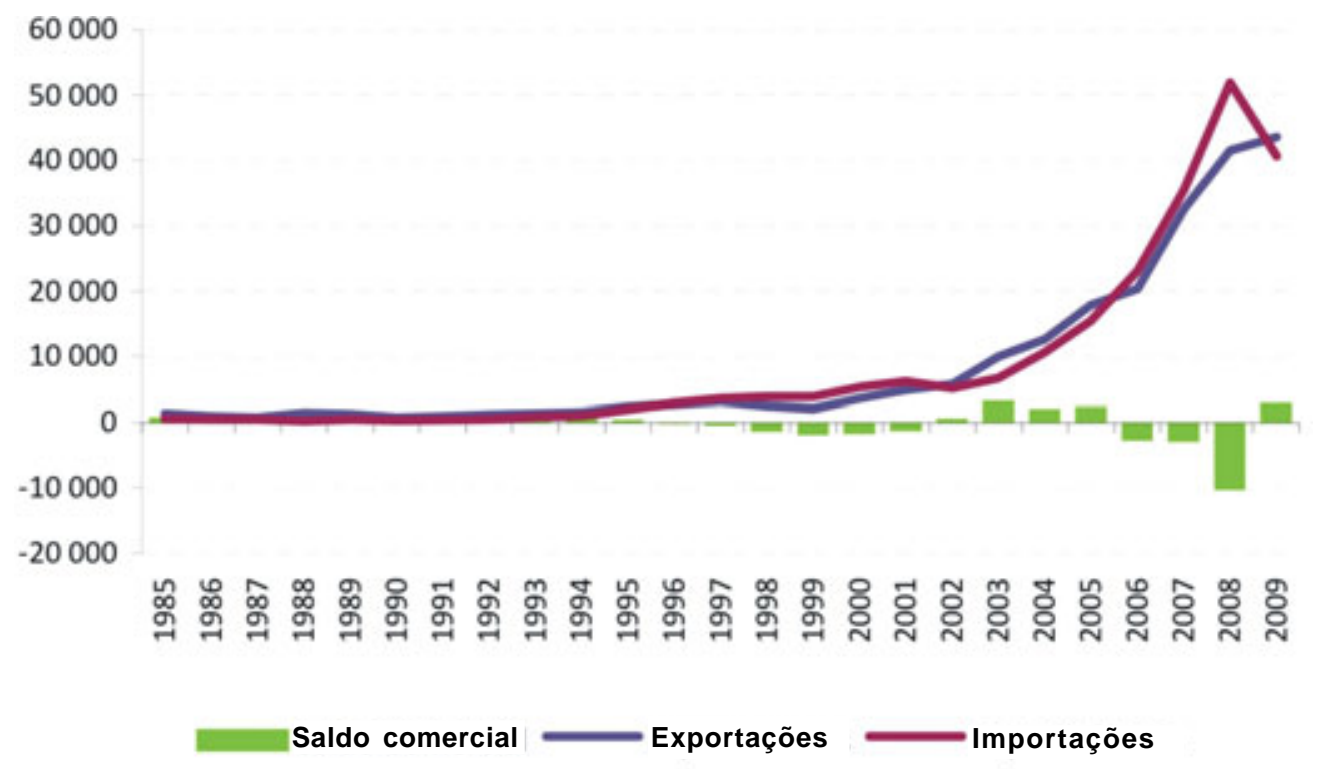

FONTE: Bárcena e Rosales (2010) a partir dos dados da Cepal.

GRÁFICO 4 - EXPORTAÇÕES, IMPORTAÇÕES E SALDO COMERCIAL DO MÉXICO E DA AMÉRICA CENTRAL COM ARPC (EM MILHÕES DE US\$)

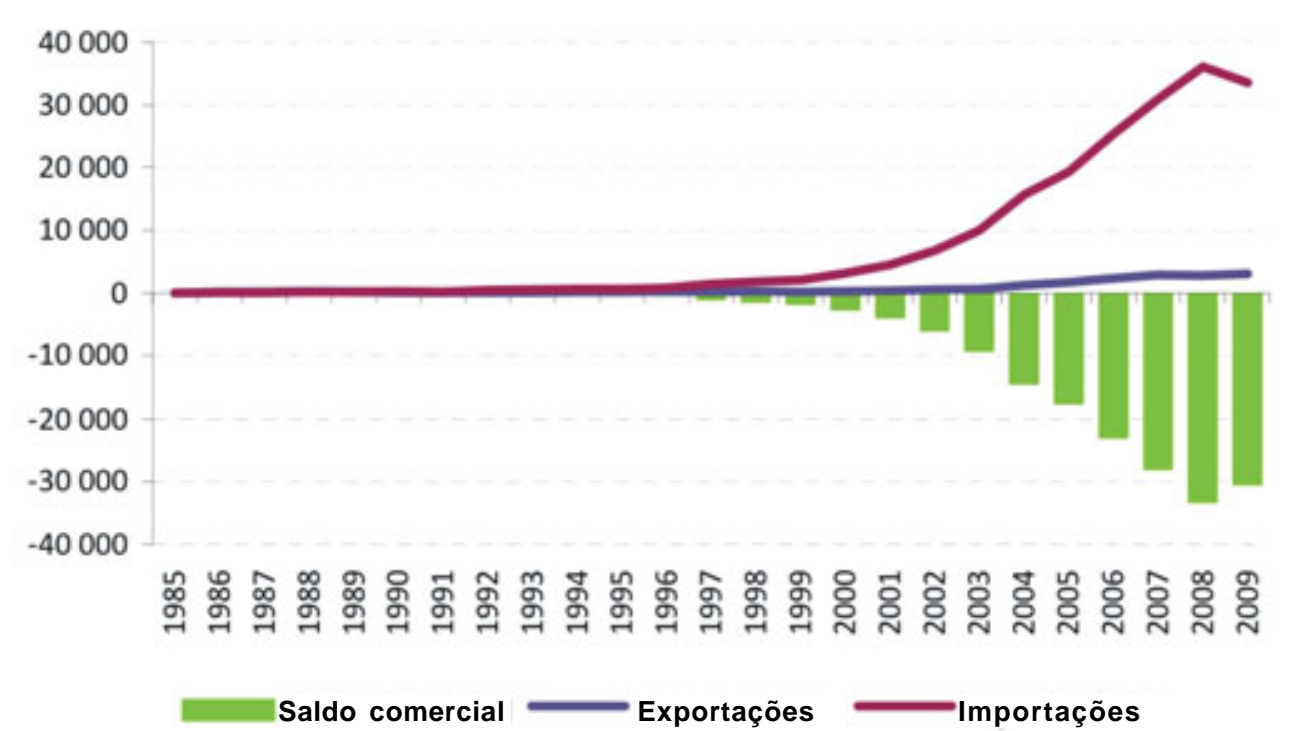

FONTE: Bárcena e Rosales (2010) a partir dos dados da Cepal.

Em segundo lugar, a explosão das exportações latino-americanas, a partir de 2002, concentra-se em commodities e recursos energéticos e minerais. Em contrapartida, as importações vindas da RPC estão concentradas em produtos manufaturados. Por essa razão, os países da América do Sul, abundantes em recursos, foram e estão sendo os mais favorecidos com o aumento das exportações. Nessa direção, Gallagher e Porzecanski (2010) realizaram um interessante estudo dos impactos diretos e indiretos da relação 
econômica entre a RPC e América Latina e apresentam um cenário preocupante para a indústria da região. Os autores apontam que os benefícios do comércio entre os países da América Latina e China estão altamente concentrados em poucos estados e setores. Embora os autores tenham como foco toda a região, eles apontam que, em 2006, dez setores e seis estados representavam $74 \%$ de todas as exportações da América Latina para a China e o $91 \%$ de todas as exportações de commodities da América Latina para esse país (GALLAGHER \& PORZECANSKI, 2010, P. 17). Dos seis países destacados por Gallagher e Porzecanski, só o México não pertence à sub-região da América do Sul. Um quadro mais atualizado de 2009 mostra os cinco países - todos da América do Sul - e os oito setores que dominam o comércio entre a América Latina e a China, como ilustra a Tabela 1.

TABELA 1: - CINCO PAÍSES E OITO SETORES DOMINAM O COMÉRCIO AMÉRICA LATINA E CHINA

\begin{tabular}{|l|c|c|}
\hline Setor & $\begin{array}{c}\text { Porcentagem das } \\
\text { exportaçōes da América } \\
\text { Latina para a China }\end{array}$ & $\begin{array}{c}\text { País - porcentagem do total } \\
\text { das exportações para a China } \\
\text { no setor }\end{array}$ \\
\hline Cobre & 17,9 & Chile 90 \\
Aço e derivados & 17,3 & Brasil 89 \\
Soja e outras sementes & 16,8 & Brasil 83\%; Argentina 16 \\
Minérios e concentrados de metais & 13,5 & Chile 47; Peru 39 \\
Petróleo cru & 4,5 & Brasil 65; Colômbia 20 \\
Oleo de Soja e outros óleos & 4,5 & Argentina 79; Brasil 20 \\
Celulose e residuos de papel & 4,4 & Brasil 55; Chile 43 \\
Alimentos para animais - Feedstuff & 2,4 & Peru 63; Chile 30 \\
TOTAL & 81,3 & \\
\hline
\end{tabular}

Fonte: Gallagher (2010) a partir da base de dados do United Nations Commodity Trade Statistics (Comtrade).

Levando em consideração os dados apresentados, é importante observar na Tabela 2 os países da América do Sul em separado, para termos uma visão mais detalhada das particularidades da sub-região e observarmos o grau de especialização da produção que o comércio bilateral entre a RPC e os estados da América do Sul implica.

TABELA2 - CINCO PRINCIPAIS PRODUTOS DE EXPORTAÇÃO À RPC, MÉDIA 2006-2008 (PERCENTAGENS DO TOTAL)

\begin{tabular}{|c|c|c|c|c|c|c|}
\hline Pais & $\begin{array}{l}\text { Soma dos } \\
\text { cinco } \\
\text { produtos }\end{array}$ & $1^{\circ}$ Produto & $2^{\circ}$ Produto & $3^{\circ}$ Produto & $4^{\circ}$ Produto & $5^{\circ}$ Produto \\
\hline Argentina & 93 & Soja-55 & $\begin{array}{c}\text { Óleo de soja } \\
-23\end{array}$ & $\begin{array}{c}\text { Petróleo cru - } \\
10\end{array}$ & Couros -3 & $\begin{array}{l}\text { Despojos de } \\
\text { aves -2 }\end{array}$ \\
\hline Bolívia & 82 & Estanho -27 & $\begin{array}{l}\text { Minérios de } \\
\text { estanho-19 }\end{array}$ & $\begin{array}{c}\text { Petróleo cru - } \\
17\end{array}$ & $\begin{array}{l}\text { Madeira - } \\
12\end{array}$ & $\begin{array}{c}\text { Minerais } \\
\text { comuns }-07\end{array}$ \\
\hline Brasil & 81 & $\begin{array}{l}\text { Minério de } \\
\text { Ferro-44 }\end{array}$ & Soja -23 & $\begin{array}{c}\text { Petróleo cru - } \\
6\end{array}$ & $\begin{array}{l}\text { Produtos } \\
\text { de ferro }-5\end{array}$ & $\begin{array}{c}\text { Pasta } \\
\text { química de } \\
\text { madeira }-3\end{array}$ \\
\hline Chile & 93 & Cobre -50 & $\begin{array}{l}\text { Minerais de } \\
\text { cobre }-31\end{array}$ & $\begin{array}{c}\text { Pasta } \\
\text { química de } \\
\text { madeira-6 }\end{array}$ & $\begin{array}{l}\text { Minerais } \\
\text { de ferro-3 }\end{array}$ & $\begin{array}{c}\text { Despojos de } \\
\text { carne-2 }\end{array}$ \\
\hline Colômbia & 97 & $\begin{array}{c}\text { Petróleo cru- } \\
50\end{array}$ & $\begin{array}{l}\text { Derivados do } \\
\text { ferro }-40\end{array}$ & $\begin{array}{l}\text { Restos de } \\
\text { minérios não } \\
\text { ferrosos }-5\end{array}$ & Couros -3 & $\begin{array}{c}\text { Lactamas- } \\
0,5\end{array}$ \\
\hline Equador & 98 & $\begin{array}{c}\text { Petróleo cru- } \\
94\end{array}$ & $\begin{array}{l}\text { Restos de } \\
\text { minérios nãoo } \\
\text { ferrosos }-3\end{array}$ & Madeira-1 & $\begin{array}{c}\text { Artigos de } \\
\text { toucador- } \\
0,5\end{array}$ & $\begin{array}{l}\text { Despojos de } \\
\text { carne-0,5 }\end{array}$ \\
\hline
\end{tabular}




\begin{tabular}{|c|c|c|c|c|c|c|}
\hline Paraguai & 81 & Algodão-31 & Madeira-26 & Couro-24 & $\begin{array}{c}\text { Restos de } \\
\text { plásticos - } \\
7\end{array}$ & $\begin{array}{l}\text { Restos de } \\
\text { minérios não } \\
\text { ferrosos }-5\end{array}$ \\
\hline Peru & 83 & $\begin{array}{c}\text { Minerais de } \\
\text { cobre }-39\end{array}$ & $\begin{array}{l}\text { Despojos de } \\
\text { carne }-16\end{array}$ & $\begin{array}{c}\text { Petróleo cru - } \\
10\end{array}$ & $\begin{array}{l}\text { Mineral de } \\
\text { chumbo-9 }\end{array}$ & $\begin{array}{c}\text { Minerais } \\
\text { ferrosos }-8\end{array}$ \\
\hline Uruguai & 81 & Soja - 46 & $\begin{array}{c}\text { Pasta } \\
\text { Química de } \\
\text { madeira-13 }\end{array}$ & Lã -9 & $\begin{array}{c}\text { Gordura de } \\
\text { lã }-8\end{array}$ & Couros -5 \\
\hline Venezuela & 64 & $\begin{array}{c}\text { Petróleo cru- } \\
51\end{array}$ & $\begin{array}{c}\text { Minerais } \\
\text { ferrosos }-9\end{array}$ & $\begin{array}{c}\text { Fundição } \\
\text { especular-2 }\end{array}$ & $\begin{array}{c}\text { Minerais } \\
\text { em bruto - } \\
1\end{array}$ & $\begin{array}{l}\text { Fibras para } \\
\text { tecidos }-0,5\end{array}$ \\
\hline
\end{tabular}

FONTE: Cepal, a partir da base de dados da Comtrade.

Em contrapartida, as exportações da China para a América Latina são compostas, fundamentalmente, por produtos eletrônico e mecânicos. Por essa razão, os países da América do Sul como o Brasil e a Argentina, que possuem um parque industrial considerável, são os mais prejudicados com o desenvolvimento dessa especialização comercial. As rispidezes derivadas da concorrência chinesa foram mais visíveis em janeiro de 2005 como o fim do Acordo Multifibras, "que garantia alguns países latino-americanos uma quota no mercado estadunidense e cuja finalização afetou suas exportações têxteis e favoreceu substantivamente às da China”. Isso afetou de maneira dramática os países membros do Acordo de LivreComércio da América Central (Cafta), além do México. Mais precisamente, a sub-região que assinou acordos de livre-comércio com os Estados Unidos. Todavia, é na América do Sul onde existe uma maior complementaridade, embora a recente entrada de produtos manufaturados chineses afete diretamente os setores industriais brasileiros e argentinos. $\mathrm{O}$ impacto foi sentido pelas maiores economias do Mercado Comum do Sul (Mercosul) e foi só em agosto de 2010 que ambos países esboçaram uma reação conjunta para negociar com a RPC (SIMÃO, 2010). Retomaremos esse ponto na última seção de nossa análise, prevendo novos desdobramentos como resposta à especialização clássica centro-periferia, que estaria configurando-se a partir do comércio entre os países da América do Sul e a RPC.

\section{III.2. Os investimentos externos diretos da RPC} na América do Sul

Outro ponto importante a ser destacado é o crescimento dos fluxos de investimento direto (IED) da China para a América do Sul (ver tabela 3). Todavia, resulta complicado analisar em detalhe algumas cifras extraídas do site do Ministério de Comércio da China, já que os dados indicam que, do fluxo total de investimentos para América Latina em 2007 (US\$ 4,902 bilhões), US\$ 4,478 bilhões foram para paraísos fiscais como as Ilhas Caimã e as Ilhas Virgens Britânicas, conforme a Tabela 4.

TABELA 3 - INVESTIMENTO DIRETO EXTERNO CHINA-AMÉRICA LATINA (EM MILHÕES DE US\$)

\begin{tabular}{|c|c|c|c|c|c|}
\hline $\mathbf{2 0 0 3}$ & $\mathbf{2 0 0 4}$ & $\mathbf{2 0 0 5}$ & $\mathbf{2 0 0 6}$ & $\mathbf{2 0 0 7}$ & $\mathbf{2 0 0 8}$ \\
\hline 1038,15 & 1762,72 & 6466,16 & 8468,74 & 4902,41 & 3677,25 \\
\hline
\end{tabular}

FONTE: Ministério de Comércio da China.

TABELA 4 - INVESTIMENTO DIRETO EXTERNO (IED) (EM MILHÕES DE US\$)

\begin{tabular}{|l|c|c|c|c|c|c|}
\hline & $\mathbf{2 0 0 3}$ & $\mathbf{2 0 0 4}$ & $\mathbf{2 0 0 5}$ & $\mathbf{2 0 0 6}$ & $\mathbf{2 0 0 7}$ & $\mathbf{2 0 0 8}$ \\
\hline Argentina & 1 & 1,12 & 0,35 & 6,22 & 36,69 & 10,82 \\
Bahamas & 1,03 & 43,56 & 22,95 & 2,72 & 38,99 & 55,91 \\
Barbados & - & - & - & 1,85 & 0,41 & 0,82 \\
Belize & - & - & - & - & - & 0,06 \\
Bolivia & - & - & 0,08 & 18,00 & 1,97 & 4,14 \\
Brasil & 6,67 & 6,43 & 15,09 & 10,09 & 51,13 & 22,38 \\
\hline
\end{tabular}




\begin{tabular}{|c|c|c|c|c|c|c|}
\hline Chile & 0,20 & 0,55 & 1,80 & 6,58 & 3,83 & 0,93 \\
\hline Colômbia & - & 4,53 & 0,96 & 3,36 & 0,22 & 6,76 \\
\hline Cuba & 1,43 & - & 1,58 & 30,37 & 6,58 & 5,56 \\
\hline Equador & 0,27 & 0,30 & 9,07 & 2,46 & 3,58 & 9,42 \\
\hline Granada & & & & & & 0,12 \\
\hline Guiana & - & - & - & - & 60,00 & - \\
\hline Honduras & 0,13 & 1,38 & - & 0 & 4,38 & 0,90 \\
\hline Ilhas Cayman & 806,61 & 806,61 & 5162,75 & 7832,72 & 2601,59 & 1524,01 \\
\hline Ilhas Virgens & 209,68 & 385,52 & 1226,08 & 538,11 & 1876,14 & 2104,33 \\
\hline Jamaica & - & - & - & - & - & 2,14 \\
\hline México & 0,03 & 27,10 & 3,55 & 3,69 & 17,16 & 5,63 \\
\hline Panamá & 0,01 & 0,10 & 8,36 & 0 & 8,33 & 6,52 \\
\hline Paraguai & - & - & - & - & - & 3,00 \\
\hline Peru & 0,12 & 0,22 & 0,55 & 5,40 & 6,71 & 24,55 \\
\hline Rep. Dominicana & - & - & - & - & - & 0,06 \\
\hline $\begin{array}{l}\text { S. Vicente e } \\
\text { Granadinas }\end{array}$ & 5,60 & - & 2,82 & 2,91 & 5,88 & 9,46 \\
\hline Suriname & 0,65 & 1,13 & 2,77 & - & 17,57 & 2,42 \\
\hline Uruguai & 0,55 & - & - & - & 0,48 & - \\
\hline Venezuela & 6,22 & 4,66 & 7,40 & 18,36 & 69,53 & 9,78 \\
\hline
\end{tabular}

FONTE: o autor, a partir de dados do Ministério do Comércio da China.

Não obstante, se observarmos o destino dos IEDs chineses poderemos ter uma visão mais precisa sobre a expansão da RPC no subcontinente. Uma recente pesquisa de Scissors (2011), da Heritage Foundation, foi de muita ajuda para precisar o tipo, o montante e o destino dos investimentos chineses na América do Sul. Segundo a Tabela 5, a sub-região é o destino principal dos IEDs chineses, que podem ser divididos em três principais categorias, de acordo com seus propósitos: a) "orientados aos recursos naturais" (natural resource-seeking); b) "orientados ao mercado" (market-seeking) e c) "orientados à eficiên- cia” (efficiency-seeking). Como mostram as tabelas 3, 4 e 5, a grande maioria dos IEDs com destino à América do Sul são orientados à exploração de recursos naturais, em setores de grande demanda da RPC, como cobre, aço, petróleo e soja. Ademais, podemos observar investimentos em infraestrutura ligados a facilitar o escoamento desses produtos. Segundo os dados dessa pesquisa, não só os países da América do Sul foram os mais beneficiados com os IEDs oriundos da RPC - como mostra a Tabela 5 -, mas o Brasil aparece como o principal receptor da região e do mundo em 2010, segundo os dados totais SCISSORS (2011).

TABELA 5 - INVESTMENTOS EXTERNOS DIRETOS DA RPC NAAMÉRICA LATINA

\begin{tabular}{|c|c|c|c|c|c|c|c|c|}
\hline Ano & Mês & Investidor & $\begin{array}{l}\text { Quant. } \\
\text { milhōes } \\
\text { (US\$) }\end{array}$ & $\%$ & Parceiro & Setor & Subsetor & Pais \\
\hline 2005 & Maio & Minnetals & 500 & & & Metais & & Cuba \\
\hline 2005 & Junho & Minnetals & 550 & 50 & Coldeco & Metais & AçO & Chile \\
\hline 2005 & Setembro & CNPC e Sinopec & 1420 & & Encana & Energia & Petróleo & Equador \\
\hline 2006 & Abril & Sinopec & 240 & & Petrobras & Energia & Gás & Brasil \\
\hline 2007 & Fevereiro & $\begin{array}{l}\text { Grupo Iiderado por Zijin } \\
\text { Mining }\end{array}$ & 190 & & Monterrico & Metais & Cobre & Peru \\
\hline 2007 & Junho & Chalco & 790 & & Peru Copper & Metais & Cobre & Peru \\
\hline 2007 & Dezembro & $\begin{array}{l}\text { Minmetals and Jiangxi } \\
\text { Copper }\end{array}$ & 450 & & $\begin{array}{l}\text { Northern Peru } \\
\text { Copper }\end{array}$ & Metais & Cobre & Peru \\
\hline 2008 & Maio & Chinalco & 2160 & & & Metais & Cobre & Peru \\
\hline 2009 & Janeiro & Huawei Technologies & 240 & & Costa Rica & Tecnologia & Telecom & Costa Rica \\
\hline 2009 & Fevereiro & Shougang Group & 1000 & & & Metais & Ferro & Peru \\
\hline 2009 & Julho & China Railways & 7500 & & & Transporte & Ferrovias & Venezuela \\
\hline
\end{tabular}




\begin{tabular}{|c|c|c|c|c|c|c|c|c|}
\hline 2009 & Setembro & $\begin{array}{l}\text { State Construction } \\
\text { Engineering }\end{array}$ & 100 & 2,75 & Baha Mar Resort & Turismo & & Bahamas \\
\hline 2009 & Novembro & Wuhan Iron and Steel & 400 & 22 & MMX Mneracao & Metais & Ferro & Brasil \\
\hline 2009 & Dezembro & $\begin{array}{l}\text { China Railway Construction } \\
\text { and Tongling Nonferrous }\end{array}$ & 650 & & $\begin{array}{l}\text { Corniente } \\
\text { Rescurces }\end{array}$ & Metais & Cobre & Chile \\
\hline 2009 & Dezembro & Hebei Zhongxin & 400 & & & Transporte & Autos & México \\
\hline 2010 & Fevereiro & Sany Heavy Industry & 200 & & & Imóveis & Construção & Brasil \\
\hline 2010 & Marco & $\begin{array}{l}\text { East China Mneral } \\
\text { Exploration and } \\
\text { Development Bureau } \\
\text { (Jiangsu) }\end{array}$ & 1200 & & Itaminas & Metais & Ferro & Brasil \\
\hline 2010 & Marcó & CNOOC & 3100 & 50 & Bridas & Energia & & Argentina \\
\hline 2010 & Marco & Sinomach & 140 & & & Agricultura & & Venezuela \\
\hline 2010 & Marco & $\begin{array}{l}\text { China State Construction } \\
\text { Engineering }\end{array}$ & 2500 & & Baha Mar Resort & Imóveis & & Bahamas \\
\hline 2010 & Abril & CNPC & 900 & & & Energia & Petróleo & Venezuela \\
\hline 2010 & April & Chongqing Food Group & 320 & & & Agricultura & & Brasil \\
\hline 2010 & May & State Grid & 990 & & $\begin{array}{l}\text { Cobra, Elecnor } \\
\text { and Isolux }\end{array}$ & Energia & & Brasil \\
\hline 2010 & May & Sinochem & 3070 & 40 & Peregrino field & Energia & Petróleo & Brasil \\
\hline 2010 & June & Sinohydro & 2300 & & $\begin{array}{l}\text { Coca Codo } \\
\text { Sinclair }\end{array}$ & Energia & Hidro & Ecuador \\
\hline 2010 & August & Gezhouba & 670 & & Hidropaute & Energia & Hidro & Ecuador \\
\hline 2010 & August & Chery & 700 & & & Transporte & Autos & Brasil \\
\hline 2010 & October & Sinopec & 7100 & 40 & Repsol & Energia & Petróleo & Brasil \\
\hline 2010 & October & Minmetals & 2500 & & & Energia & Cobre & Peru \\
\hline 2010 & November & CNOOC & 2470 & 30 & Pan American & Energia & Petroleo & Argentina \\
\hline 2010 & November & CNPC and Sinopec & 610 & & & Energia & Petróleo & Ecuador \\
\hline 2010 & December & Sinopec & 2.450 & & Occidental & Energia & Petróleo & Argentina \\
\hline 2010 & December & $\mathrm{CIC}$ & 200 & & & Finanças & Investimentos & Brasil \\
\hline 2010 & December & CITIC & 400 & & & Real Estate & Construçăo & Venezuela \\
\hline 2010 & December & Three Gorges & 200 & & & Energia & Hidro & Ecuador \\
\hline TOTAL & & & 49310 & & & & & \\
\hline
\end{tabular}

FONTE: Scissors (2011).

\section{QUADRO 1 - INVESTIMENTOS MAIS DESTACADOS}

Argentina: As companhias estatais chinesas tem interesse no setor petroleiro argentino. A companhia estatal argentina Energía Argentina Sociedad Anónima (Enarsa) tem mostrado intenção em colaborar com as companhias chinesas para exploração de petróleo offshore na costa do Atlântico Sul. Ainda em 2010, foram ratificados investimentos na ordem de US\$ 600 milhões por parte da Companhia Tierra del Fuego Energia e Química, de capital chinês, para a exploração de gás na patagônia argentina (RATIFICAN UMA INVERSIÓN, 2010). Em relação ao setor de minério, os investimentos foram modestos, mas em 2005 foi dado um primeiro passo quando uma companhia chinesa comprou a mina desativada de Sierra Grande, na província de Rio Negro. Essa mina contém jazidas de ferro, cobalto e outros minerais. No setor de infraestrutura, o governo argentino mostrou-se interessado em revitalizar e ativar as rotas para o oceano Pacífico por meio da Cordilheira dos Andes. Especificamente, os chineses mostraram interesse nas passagens do Cristo Redentor e de Águas Negras, que seriam as prioridades.

Brasil: O foco dos investimentos tem sido nos setores da mineração do ferro e do aço assim como no petróleo. A empresa de mineração brasileira de capital privado, Vale do Rio Doce, tem iniciado conversas em 2004 com a companhia chinesa Baosteel para a exploração de ferro. Além disso, a mesma Vale tem se aproximado da Monmetals, outra empresa chinesa. Em 2006, a companhia chinesa Metals and Metallurgical Construction Group of China investiu US\$ 235 milhões em um acordo com a Mineradora Gerdau S.A. No que se refere ao petróleo, a empresa estatal brasileira Petrobrás assinou, desde 2004, vários acordos com as estatais petroleiras chinesas: em 2004 com a Sinopec para a extração de petróleo cru, refinamento e construção de oleodutos no Brasil; em julho de 2005 com a Sinochem para vender 12 milhões de barris de petróleo por dia por um montante de US\$ 600 milhões; em 2010, a Sinopec também investiu US\$ 7,1 bilhões na empresa Repsol no Brasil (HOOK, 2010). Além disso, a RPC investiu US $\$ 4,8$ bilhões para modernizar o sistema de transporte ferroviário brasileiro para facilitar o escoamento das exportações. 
Chile: Em 2006, a companhia chinesa Minmetals e o Banco de Desenvolvimento da China fecharam um acordo com a empresa estatal de cobre chilena Codelco para incrementar sua capacidade produtiva com o objetivo de aumentar as exportações para a RPC. A maior parte dos investimentos chineses focam-se no setor de mineração.

Peru e Bolívia: os investimentos chineses predominam na área de mineração, infraestrutura e, em menor medida, no setor petroleiro e de pesca. O mais destacado na área de mineração envolve o consórcio chinês Shandong Luneng com o Peru e a Bolívia. Em 27 fevereiro de 2006, o Congresso peruano aprovou um importante projeto que envolve um investimento de aproximadamente US\$ 2 bilhões por parte desse consórcio chinês para reformar o porto de Tacna e US\$ 8 bilhões para a construção de uma rodovia e um estrada de ferro que conecte a mina de El Mutún, jazida que fica no leste da Bolívia, com o porto de Tacna, na costa do oceano Pacífico.

FONTE: Ellis (2009) e Gallagher e Porzecanski (2010), atualizados pelo autor.

\section{III.3. Interdependência assimétrica}

Embora o relacionamento crescente da RPC com os países da América do Sul tenha de fato contribuído para a recuperação econômica da subregião, esse vínculo é marcadamente assimétrico. Em outros termos, para manterem-se na trilha do crescimento, os países da América do Sul dependem mais da RPC do que a China deles.

"A China está entre os três principais sócios comerciais de vários países latino-americanos. Não obstante, devido à assimetria no seu tamanho em relação aos países latino-americanos, a China é muito mais importante economicamente para América Latina do que a região é para a China. Por exemplo, o Brasil, que é o maior exportador da América Latina para a China, ocupa o décimo quarto lugar entre seus provedores, representando somente $1,5 \%$ do total das suas importações, e nenhum outro país da região figura entre os vinte principais na fonte de importação" (JENKINS, 2009, p. 2).

Mesmo levando em consideração a América Latina e o Caribe como uma totalidade, ela recebe somente 3\% do total das exportações da RPC para a região e abastece com o 3,8\% do total de suas importações (JENKINS, DUSSEL PETERS \& MESQUITA MOREIRA, 2008, p. 237). A China, em contrapartida, é um dos cinco principais destinos exportadores de Argentina, Brasil, Chile, Cuba e Peru.

TABELA 6 - LUGAR QUE OCUPAA CHINA EM PAÍSES SELECIONADOS DAAMÉRICA LATINA

\begin{tabular}{|c|c|c|c|c|}
\hline \multirow[t]{2}{*}{ País } & \multicolumn{2}{|c|}{ Exportações } & \multicolumn{2}{|c|}{ Importações } \\
\hline & 2000 & 2008 & 2000 & 2008 \\
\hline Argentina & 6 & 2 & 4 & 3 \\
\hline Bolivia & 12 & 10 & 8 & 6 \\
\hline Brasil & 12 & 1 & 11 & 2 \\
\hline Chile & 5 & 1 & 4 & 2 \\
\hline Colômbia & 35 & 4 & 15 & 2 \\
\hline Costa Rica & 26 & 2 & 16 & 3 \\
\hline Equador & 13 & 9 & 10 & 2 \\
\hline El Salvador & 35 & 16 & 18 & 5 \\
\hline Guatemala & 30 & 18 & 15 & 4 \\
\hline Honduras & 35 & 11 & 18 & 7 \\
\hline México & 25 & 5 & 6 & 3 \\
\hline Nicaragua & 19 & 14 & 18 & 4 \\
\hline Panamá & 22 & 4 & 17 & 4 \\
\hline
\end{tabular}




\begin{tabular}{|lrrrr|}
\hline Paraguai & 11 & 9 & 4 & 1 \\
Peru & 4 & 2 & 13 & 2 \\
Uruguai & 5 & 8 & 6 & 3 \\
Venezuela & 37 & 3 & 18 & 3 \\
\hline
\end{tabular}

FONTE: Cepal.

A Tabela 6 mostra o grau de importância que a RPC passou a ter para os países latino-americanos, sobretudo para os sulamericanos, em um período relativamente curto de oito anos. Este cenário de interdependência assimétrica, se bem se mostrou uma interessante alternativa frente aos rígidos constrangimentos do "Consenso de Washington”, tem que ser levado em consideração para as estratégias políticas de longo prazo.

III.4. A Diplomacia da aproximação na América do Sul

O estreitamento de vínculos diplomáticos en- tre a RPC e os países da América do Sul, em consonância com a bonança comercial, aconteceu em 2004, após a visita do Presidente Hu Jintao a cinco países latino-americanos - Chile, Argentina, Brasil, Venezuela e Cuba -, no marco da reunião de cúpula da Cooperação Econômica da Ásia e do Pacífico (APEC), realizada no Chile. O resultado da visita do Presidente chinês foi a assinatura de 39 acordos comerciais ${ }^{3}$ e o compromisso de investir US\$ 100 bilhões na região nos dez anos seguintes. O país da região que mais investimentos receberia seria a Argentina, com um montante de US\$ 20 bilhões (ELLIS, 2005; LANDAU, 2005).

TABELA 7 - NÚMERO DE VISITAS PRESIDÊNCIAS ENTRE A RPC EAAMÉRICA LATINA

\begin{tabular}{|c|c|c|}
\hline Data e Presidente & China a América Latina & América Latina a China \\
\hline 2001 - Jiang Zemin & $\begin{array}{l}\text { Chile, Argentina, Uruguai, Brasil, } \\
\text { Venezuela e Cuba }\end{array}$ & Peru, Chile, México e Venezuela \\
\hline 2002 - Jiang Zemin & México-visita não oficial ${ }^{*}$ & Equador e Uruguai \\
\hline 2003 - Jiang Zemin & & Equador, Cuba e Guiana \\
\hline 2004 - Hu Jintao & Chile, Brasil, Argentinae Cuba & $\begin{array}{l}\text { Argentina, Brasil, Venezuela e } \\
\text { Suriname }\end{array}$ \\
\hline 2005- Hu Jintao & México & Peru e Colômbia \\
\hline 2006- Hu Jintao & & Venezuela e Bolivia \\
\hline 2007 - Hu Jintao & & Costa Rica \\
\hline 2008- Hu Jintao & Peru, Costa Rica e Cuba & $\begin{array}{l}\text { Peru, Chile, México, Brasil e } \\
\text { Venezuela }\end{array}$ \\
\hline 2009- Hu Jintao & & $\begin{array}{c}\text { Chile, Brasil, Venezuela e } \\
\text { Uruguai }\end{array}$ \\
\hline 2010- Hu Jintao & Brasil, Venezuela e Chile & Perü e Argentina ${ }^{-\cdots .}$ \\
\hline
\end{tabular}

FONTE: Bárcena e Rosales (2010) a partir do Governo Central da República Popular da China (PEOPLE'S REPUBLIC OF CHINA, 2011), atualizado pelo autor.

NOTAS: * Reunião da APEC:

** Visitas suspensas a causa do terremoto na província chinesa de Qinghai;

*** O Presidente Alan Garcia prorrogou a sua visita marcada para finais de abril de 2010;

**** A Presidente Cristina F. de Kirchner cancelou a visita oficial a China marcada para janeiro de 2010. A visita foi efetivada em julho de 2010.

3 Os acordos seriam sobre comércio, investimento, aviação, tecnologia espacial, turismo e educação. 
Além disso, os maiores sucessos diplomáticos da China foram, em primeiro lugar, ter conseguido o reconhecimento como "economia de mercado" no âmbito da Organização Mundial do Comércio (OMC), primeiro por parte do Brasil, seguido por outros países incluindo a Argentina, e, em segundo lugar, a assinatura de dois tratados de livre-comércio com o Chile e com o Peru. No que se refere ao primeiro ponto, esse reconhecimento tem implicações jurídicas importantes no âmbito da OMC, além das econômicas e políticas (TORTORIELLO, 2004). Reconhecer a China como economia de mercado implica dar ao país as condições de utilizar as regras plenas da OMC, em vez de obrigá-la a sujeitar-se às regras especiais para economias que não sejam de mercado. Isto é, eventuais litígios comerciais devem ser levados à OMC e evitar que um país aplique represálias comerciais ou medidas antidumping unilateralmente contra a China. Na prática, isso significa que as possibilidades de utilizar instrumentos de defesa comercial contra a entrada de produtos chineses diminuem e aumentam os empecilhos ou os custos - para a abertura de painéis contra a China. A RPC, em troca, concedeu ao Brasil benefícios nos setores aeronáutico, no caso da Embraer, e agrícola, na exportação de soja, como afirmou o então Chanceler brasileiro Celso Amorim (SEVARES, 2006; LAMAS, 2007; VADELL, 2007).

Em relação à assinatura dos TLCs, a RPC, estimulada por suas necessidades de recursos naturais e pelo ambiente propício para os negócios, firmou acordos com dois países da América do Sul e, recentemente, com um da América Central $^{4}$. Primeiro foi com o Chile em 20065 , acordo ratificado em 2007. Depois veio o acordo com o Peru em 2009, tratado que foi ratificado em 2010. Esses acontecimentos, além das implicações puramente econômicas, assinalam desdobramentos geopolíticos regionais de maior complexidade que serão apontados na última seção.

\section{O PERÍODO POSTERIOR AO CONSENSO} DE WASHINGTON NAAMÉRICA LATINA

O cenário futuro parece ser de continuidade e consolidação das parcerias comerciais entre a China e os países da América do Sul, principal-

\footnotetext{
4 A RPC assinou um TLC com a Costa Rica em 2010.

5 O conteúdo integral do acordo entre o Chile e a RPC pode ser consultado em Diário Oficial de la Republica de Chile (2006).
}

mente aqueles produtores de commodities e recursos energéticos. Assim, a crescente presença da RPC na sub-região abriu o leque de oportunidades e potencialidades para os países em desenvolvimento ricos em recursos. Esses países, que vinham de duros golpes econômicos, começaram, no decorrer do novo século, a olhar mais para o "Pacífico" do que para o "Atlântico". O fracasso das reformas neoliberais sustentadas pelo CW e a crise financeira global de 2008 parecem ter rompido a possibilidade de receitas unívocas de reformas para os países do Sul. É nesse cenário que a RPC surge como principal fator na recuperação dos países sul-americanos, como um ator presente na sub-região e como um desafio para os projetos de integração regional.

Para caracterizar o que denominamos como Consenso do Pacífico seria interessante retomar a noção de consenso assim como apresentada por Williamson (1990). O objetivo de Williamson nesse trabalho é identificar, em primeiro lugar, o que significa "reformas econômicas" para Washington, em um contexto de reestruturação da dívida dos países latino-americanos e de crise fiscal do Estado. Em segundo lugar, o autor explica que o conceito "Washington" era mais complexo do que o nome da capital dos EUA.

“Washington”, para Williamson, aglutinaria um conjunto de instituições nacionais (dos EUA) e internacionais articuladas por meio de uma ideologia comum - a ideologia dominante -, sustentadas nos alicerces do poder econômico e político global, no cenário otimista do fim da Guerra Fria. Assim, o Congresso dos EUA, os membros da alta administração tecnocrática das instituições financeiras internacionais, as agências do governo dos EUA, o Banco Central dos EUA e um conjunto de think tanks formariam o bloco hegemônico de "Washington”, cujo projeto global condensa-se no popular termo "globalização" (ARRIGHI, 2008). Contudo, deve-se fazer a ressalva de que esse projeto específico era pensado e aplicado para a América Latina, podendo ser estendido para o conjunto dos países em desenvolvimento de outros continentes, mas nunca para os EUA, porque, como lembra o autor, Washington "não pratica sempre o que prega para os estrangeiros" (WILLIAMSON, 1990, P. 2). Isso indica que o CW não significou uma mecânica imposição do modelo de mercado ocidental - dos países desenvolvidos para os países em desenvolvimento -, mas a articulação hegemônica de um modelo de ajuste e de reformas aceleradas que in- 
cluíam a liberalização comercial e financeira e as privatizações realizadas em tempo recorde com o intuito de adaptar e disciplinar esses países no "caminho certo" da modernidade e do primeiro mundo. Dessa maneira, o CW é, sobretudo, um específico padrão de interdependência assimétrica entre atores internacionais e transnacionais historicamente delimitada e mediada por um conjunto de instituições internacionais. Caracteriza-se como uma relação "Norte-Sul” imbuída da ideologia econômica neoliberal, apresentada como a única via para o desenvolvimento no formato de um pacote de políticas para os países em desenvolvimento e subdesenvolvidos.

Os elementos consensuais desse modelo adquiriram força depois do fim da Guerra Fria com o subseqüente discurso do "fim da história", o fracasso dos modelos econômicos e políticos autoritários do "socialismo real” e a perda de confiança nas políticas de planejamento estatal abaladas pela crise fiscal do Estado nos países em desenvolvimento, principalmente depois da crise da dívida externa na década de 1980. O Consenso de Washington foi implementado segundo o receituário, de maneira mais ou menos acabada, por governos em sua maioria eleitos democraticamente, e intermediados pelas instituições financeiras internacionais: FMI e Banco Mundial. Os empréstimos e linhas de créditos dessas instituições foram outorgados aos países condicionados a políticas de ajuste econômico cujos pilares foram: (i) uma ampla liberalização financeira; (ii) abertura comercial unilateral; (iii) privatização das empresas públicas; (iv) desregulamentação e (v) políticas de corte de gastos e ajuste orçamentário ${ }^{6}$.

Na virada do milênio, os magros resultados apos uma década de reformas e uma nova crise econômica dos países em desenvolvimento estimularam uma onda crítica do CW, inclusive por economistas do mainstream. Nesse cenário, já no século XXI, houve o apelo para a formação de novos e alternativos "consensos", incluindo o

\footnotetext{
6 Consideramos esses quatro pilares os fundamentais para entender as reformas liberalizantes. As dez famosas recomendações apontadas por Williamson (1990) são: (i) a disciplina fiscal; (ii) a reestruturação do gasto do Estado; (iii) as reformas impositivas; (iv) a liberalização das taxas de juros; ( $v$ ) a implementação de uma taxa de câmbio competitiva; (vi) a liberalização comercial; (vii) a liberalização dos investimentos; (viii) as privatizações; (ix) as desregulamentações; $(x)$ uma forte proteção aos direitos de propriedade.
}

Consenso de Monterrey, o Consenso de Copenhagen, o Consenso de México e o Consenso de Buenos Aires ${ }^{7}$. Segundo Kennedy (2010, P. 467), os mal-entendidos, as emendas e os desafios enfrentados pelo CW conformaram o cenário crítico em que surge, também, a idéia de "Consenso de Pequim".

Em 2004, em época de plena recuperação econômica global e de crescimento dos países da América Latina, Joshua Cooper Ramo publicou um pequeno livro intitulado The Beijing Consensus, cuja repercussão foi imediata. A partir dessa obra popularizou-se o termo "Consenso de Pequim" para compreender o estilo ou modelo de desenvolvimento que a RPC estaria implementando, a partir de uma série de reformas econômicas. Nas palavras do autor: "China is marking a path for other nations around the world who are trying to figure out not simply how to develop their countries, but also how to fit into the international order in a way that allows them to be truly independent, to protect their way of life and political choices in a world with a single massively powerful centre of gravity. I call this new centre and physics of power and development the Beijing Consensus"8 (RAMO, 2004).

O Consenso de Pequim, na versão de Ramo, estaria baseado, pois, em três características que

7 O Consenso de Monterrey foi promovido pela Organização das Nações Unidas e pelo antigo secretário geral da OMC, Michael Moore, com o objetivo de reduzir a pobreza. O Consenso de Copenhagen consistia em uma série de questões feitas a economistas a respeito de dez propostas ou passos a seguir para incrementar o bem-estar global. O Consenso de México apontava para as questões de igualdade de gênero na América Latina e no Caribe. O Consenso de Buenos Aires foi um documento assinado em 2003 pelos presidentes do Brasil e da Argentina, Luiz Inácio Lula da Silva e Nestor Kirchner. Os países líderes do Mercosul comprometiam-se com a integração e com o desenvolvimento de tecnologia, participação conjunta em foros multilaterais, negociação com a Área de Livre-Comércio das Américas (ALCA), meio ambiente e gestão da dívida pública. Ver matéria da revista Foreign Policy (TOO MUCH CONSENSUS, 2004) e o documento do Consenso de Buenos Aires (BRASIL, 2003).

8 “A China está desenhando um caminho para outras nações ao redor do mundo que estão tentando descobrir não apenas como desenvolver seus países, mas também como encaixar-se na ordem internacional de um modo que os permita ser verdadeiramente independentes, para proteger seu estilo de vida e suas escolhas políticas em um mundo com um centro de gravidade maciçamente poderoso. Eu chamo esse novo centro e física de poder e desenvolvimento de o Consenso de Pequim”. 
determinariam a maneira como uma nação em desenvolvimento pode achar o seu lugar na economia global e a sua própria inserção no sistema internacional. A primeira característica seria a inovação e a constante experimentação. A segunda é a ênfase que a China dá à qualidade de vida fundamentalmente sustentabilidade e eqüidade para tratar os assuntos de desenvolvimento, deixando em segundo lugar as medições de PIB per capita. A terceira característica está relacionada com o enfoque da "autodeterminação" (idem), deixando de lado as imposições do Banco Mundial e do FMI. Ramo, citando um acadêmico chinês, afirma que o respeito pela autodeterminação dos Estados está ligado à resistência ao hegemonismo, e isso constitui uma importante dimensão política da expansão econômica chinesa. Segundo o autor, "as nações em desenvolvimento são a principal força para conter o hegemonia e salvaguardar a paz mun-dial”. Embutida nesse argumento está a estratégia de "reduzir o status de superpotência absoluta dos EUA, promovendo um mundo multipolar" (RATLIFF, 2009), pelo menos no que concerne às relações econômicas internacionais. Esse é um fator que, em grande medida, faz com que o modelo de Pequim se apresente como atrativo para outras nações em desenvolvimento, o que Ramo denomina de "carisma intelectual do Consenso de Pequim” (RAMO, 2004).

Nessa direção, de acordo com a interpretação de Ramo, o Consenso de Pequim seria um modelo particular de desenvolvimento que a RPC conseguiu implementar com relativo sucesso, cuja estratégia estaria sujeita a emulação pelos outros Estados em desenvolvimento e, implicitamente, teria um forte elemento contra-hegemônico. A interpretação de Ramo apresenta uma série de postulados normativos em relação à proposta chinesa de desenvolvimento, deixando em um segundo plano as dinâmicas que esse mesmo processo acelerado de crescimento e transformação provoca no sistema internacional. Reforçando a característica da "inovação" e eqüidade, a China ofereceria às outras nações idéias para seus próprios e particulares desafios no que tange ao desenvolvimento econômico e social.

Assim, a China agiria como uma influência positiva, espalhando essa dinâmica em três direções: a primeira, como reação às ideias ultrapassadas de Washington sobre o desenvolvimento.
Em segundo lugar, apresentando uma "nova física” que envolveria uma espécie de reação em cadeia de crescimento endógeno, onde quer que fosse copiado. Finalmente, o crescimento econômico da China serviria como ímã para alinhar as outras nações aos interesses econômicos da China. Segundo Ramo, "for both reasons of national pride and security, China wants to project its model abroad"10 (idem, p. 28).

A caracterização de Ramo, se bem pretende mais descrever o "modelo chinês" de desenvolvimento (KENNEDY, 2010) do que um padrão de interdependência, fica presa a um utopismo baseado em um raciocínio de bases fortemente normativas. Essa descrição da potencial imitação de processos produtivos e de um modelo de desenvolvimento específico não nos ajuda na compreensão das implicações geopolíticas e geoeconômicas - que envolvem a questão do desenvolvimento - dos países da América Latina e da África que experimentam uma interdependência comercial sem precedentes com a RPC. Ramo não consegue enxergar essa nova dinâmica Norte-Sul no contexto do capitalismo contemporâneo. De fato, a tendência contemporânea de aproximação entre a América do Sul e a China está muito longe de qualquer emulação de modelos de desenvolvimento. Trata-se, nesses casos, de uma complementaridade comercial dinamizada pela expansão comercial e financeira chinesa, o crescimento mundial e a elevação dos preços das commodities e dos recursos energéticos.

Essa nova relação Norte-Sul, assimétrica e complementar, na era posterior ao Consenso de Washington, entre a RPC e algumas regiões em desenvolvimento, como é o caso dos países da

9 No original: "new physics”. Dirlik faz uma crítica ao argumento de Ramo que, por razões de espaço, não podemos aprofundar neste artigo. “The problem is that Ramo's physics is a faulty as his political economy and, in the end, the Beijing Consensus appears, more than anything, to be a soles gimmick - selling China to the World, while selling certain ideas of Development to the Chinese leadership" (DIRLIK, 2007, p. 2). (“O problema é que a física de Ramo é tão faltosa quanto sua economia política e, no fim, o Consenso de Pequim parece, mais do que tudo, ser apenas um truque - vender a China para o mundo, enquanto vendendo certas idéias de desenvolvimento para a liderança chinesa”).

10 "A China, seja por razões de reputação nacional ou segurança, deseja projetar seu próprio modelo para fora”. 
América do Sul - é a que denominamos como Consenso do Pacífico. O CP não pretende descrever o funcionamento ou as características de um modelo de desenvolvimento específico, mas um tipo de relacionamento Norte-Sul na sua fase comercial-financeira, cujo desenvolvimento é uma conseqüência direta das transformações globais, da ascensão chinesa e das próprias características do desenvolvimento da RPC. Para os países da América do Sul e da África não se trata de emulação do modelo de desenvolvimento chinês. Esse não é o secreto do crescimento econômico experimentado por esses países nos últimos anos, como vários analistas têm apresentado. Eis o ponto nevrálgico da nossa questão. Trata-se, pelo contrário, de novas possibilidades de inserção internacional por parte dos países em desenvolvimento, a partir de um comércio complementar com a RPC, que pode acelerar a cristalização de um tipo de especialização nos moldes de um sistema centro-periferia e, como conseqüência, o surgimento de um renovado modelo de desenvolvimento commodity-exportador para os países periféricos.

Se realizarmos um exercício de análise prospectiva para a América do Sul, resulta muito difícil pensar em projetos de integração e de estratégias de inserção internacional, sem levar em consideração o gigante asiático como o mais importante ator extra-regional na região. Como destacado, esse relacionamento, sustentado nas trocas complementares e no comércio internacional, assemelha-se mais a um tipo de vínculo Norte-Sul do que Sul-Sul, porém muito diferente da divisão internacional do trabalho do século XIX, cujo centro era a Grã-Bretanha, o típico modelo Ocidental centro-periferia. Dessa maneira, com o objetivo de esclarecer a questão, podemos apontar as características mais salientes desse novo consenso: (i) o CP abre as margens de manobra política para países em desenvolvimento e subdesenvolvidos. $\mathrm{O}$ envolvimento da China na América Latina, mas também na África, no século XXI, apresenta-se como uma nova opção para os estados do "Sul”, em contraposição aos constrangimentos rígidos do CW. Seja mediante novas possibilidades de comércio, seja em investimentos na área de infraestrutura e na indústrias extrativas ou com ajudas financeiras para quitar dívidas externas.

(ii) A interdependência crescente entre a RPC e os países em desenvolvimento não se apresenta, no curto prazo, como uma ameaça para os EUA, e isso vale sobretudo para o hemisfério oci- dental. Não obstante, os Estados Unidos têm se preocupado com a presença chinesa na região e têm pressionado para deixar clara essa relação. Foi assim que, em abril de 2006, em uma reunião em Pequim, o então Subsecretário de Estado para o Hemisfério Ocidental dos EUA, Thomas Shannon, o vice-Ministro de Relações Exteriores da China, Dan Bingguo e o Chefe do Departamento de Assuntos Latino-Americanos, Zeng Gang, junto a outros funcionários, assinaram um acordo para criar um mecanismo regular de consulta sobre a região (CORNEJO \& NAVARRO GARCIA, 2010, p. 82). Isso significa que a China comprometeu-se a fazer uma prestação de contas periódica das suas atividades hemisféricas. Nesse sentido, as autoridades chinesas têm reiterado freqüentemente que o objetivo da RPC é defender o princípio de não intervenção nos assuntos internos de outros países e que o foco do relacionamento com os países da América Latina é estritamente econômico e não de natureza política. Esse princípio é o principal argumento chinês no intuito de evitar disputas com a superpotência e manter as redes comerciais e de investimentos. A mesma defesa do princípio de "não intervenção em assuntos internos” está casada com a intenção explícita da China de não tentar impor ideologia alguma ou promover revoluções. O paradoxo é que a defesa do princípio de “não intervenção” adotada pela RPC entra em conflito com os interesses dos EUA em algumas outras regiões, como na África ou na Ásia, nos casos específicos do Sudão e do Irã.

(iii) Em terceiro lugar, a China tem como objetivo manter e promover a estabilidade nas mais diversas regiões para, dessa maneira, garantir a segurança nos investimentos e os contratos das relações comerciais (RATLIFF, 2009).

(iv) Em quarto lugar, a RPC está surgindo como uma nova possibilidade de financiamento para os países com problemas financeiros da América do Sul. A diferença mais saliente em relação ao modelo de empréstimos das instituições financeiras internacionais como o FMI e o Banco Mundial é que a RPC não impõe condicionalidades políticas em troca de investimentos e ajuda ${ }^{11}$. As duas prin-

11 Talvez a única exceção vale para a questão do reconhecimento oficial da RPC em detrimento de Taiwan. Contudo, como expressam Cornejo e Navarro García (2010, p. 85) e já foi mencionado anteriormente, o fato que um país mantenha relações diplomáticas com Taiwan não afeta necessariamente o intercâmbio econômico com a China. 
cipais instituições chinesas de financiamento são o Banco Chinês de Desenvolvimento e o Banco de Exportação e Importação Chinês ${ }^{12}$ que, segundo uma pesquisa feita pelo jornal Financial Times, emprestaram entre 2009 e 2010 aproximadamente US\$ 110 bilhões a governos e empresas de países em desenvolvimento. Isso ultrapassou o montante de empréstimos do Banco Mundial, de meados de 2008 até meados de 2010, que foi de US\$100,3 bilhões DYER, ANDERLINI \& SENDER, 2010). Ambas as instituições bancárias chinesas provêem empréstimos com taxas preferenciais e com muitas melhores condições do que os oferecidos pelo Banco Mundial e estão fortemente apoiados pela política oficial de Pequim. Nesse ponto, o CP contrasta com a política das instituições financeiras internacionais, muito ativas com o CW. As ajudas e empréstimos chineses, além de serem mais atraentes economicamente, também o são politicamente. Não há cláusulas de condicionalidades envolvidas nos acordos, nem pressão para reformas institucionais domésticas. Em termos do Financial Times, os empréstimos impõem menos condições onerosas de transparência (idem). Cabe destacar que, além dessas duas instituições, também o Banco Central da China mostra-se muito ativo oferecendo ajuda financeira. Confiante nas possibilidades de ajuda chinesa, por exemplo, o Banco Central da Argentina assinou em 2009 um acordo de cooperação com o Banco Central da China ${ }^{13}$.

(v) Finalmente, uma característica interessante do padrão de relacionamento do CP é a estratégia bilateral de negociação, seja nas assinaturas dos TLC com três países da região, seja na negociação com os países membros do Mercosul. Foi seguindo esse padrão bilateral que a RPC articulou politicamente o reconhecimento como economia de mercado da RPC por parte do Brasil e da Argentina ${ }^{14}$.

\footnotetext{
12 Em inglês: China Development Bank e China ExportImport Bank, respectivamente.

13 Para mais detalhes dessa iniciativa da Argentina, ver: CHINA PONE A DISPOSICIÓN (2009); FIRMAN UN ACUERDO (2009).

14 O fato de o Paraguai não reconhecer a RPC dificulta também qualquer tipo de negociação partindo do Mercosul
} como bloco.
V. CONCLUSÕES: A BIFURCAÇÃO DO CP E ALGUMAS REFLEXÕES SOBRE O FUTURO DA INTEGRAÇÃO NA AMÉRICA DO SUL

Uma conseqüência direta dessas transformações geopolíticas e geoeconômicas que envolvem a RPC e a América do Sul é a bifurcação do CP, desdobramento diretamente ligado ao impacto diferenciado nos diferentes estados da sub-região. É, nesse sentido, que a expansão chinesa apresentar-se-á como um dos maiores desafios para o processo de integração na América do Sul. Como foi destacado, a explosão do comércio com a China está cristalizando a especialização comercial entre, por um lado, países produtores de commodities e de recursos energéticos e, por outro, o produtor de manufaturas, nesse caso a própria China. Dessa maneira, observando mais detidamente, o CP tem implicações diferenciadas em países com níveis de desenvolvimento diferentes. Trata-se de uma bifurcação dos impactos, que apresentará suas contradições à medida que essa particular relação Norte-Sul aprofunde-se.

Em primeiro lugar, para os países que não possuem um parque industrial importante ou não experimentaram um processo de industrialização na sua trajetória de desenvolvimento, não haverá um impacto negativo no curto prazo; muito pelo contrário, a parceria com a RPC está em seu ponto mais elevado. Os casos de Chile e do Peru são o exemplo mais destacado. Não obstante, o futuro desses países estará determinado pela nova relação Norte-Sul, uma típica relação centro-periferia na qual prima o aspecto funcional das economias subdesenvolvidas no mercado mundial baseadas na especialização na produção de commodities e de recursos naturais. Nesse cenário, a China tem um peso cada vez mais proeminente nessa dinâmica comercial em processo de consolidação. A relação que o Chile e o Peru têm atualmente com a RPC parece ser uma lua de mel que começou nos alvores do século XXI e que parece não ter fim, superando, em grande medida, os impactos negativos da crise financeira global de 2008.

Em segundo lugar, a outra face da moeda são os países como a Argentina e o Brasil, os países economicamente maiores da sub-região, que têm um setor industrial considerável e, além disso, certa responsabilidade na condução e liderança dos processos de integração regional na América do Sul. Para eles, a realidade tornar-se-á mais com- 
plexa. No Mercosul, por exemplo, os produtos industrializados oriundos da China ameaçam o setor industrial da Argentina e, ao mesmo tempo, ameaçam a indústria brasileira, que perde mercado no país vizinho, criando atritos entre ambos os parceiros regionais. A titulo de ilustração, vale a pena lembrar um recente episódio envolvendo negociações comerciais entre a Argentina e o Brasil justamente para tentar equacionar esse problema. No dia 26 de março de 2010, em um encontro em Brasília, o Secretário de Comércio Exterior do Brasil, Welber Barral, e o subsecretário de Política e Gestão Comercial do Ministério da Produção da Argentina, Eduardo Bianchi, acordaram posições em conjunto em face da política comercial da China para a região (LEO, 2010; SIMÃO, 2010). As duas maiores economias da região deram o pontapé inicial para levar adiante uma iniciativa de integração das cadeias de produção e uma política comercial e de proteção industrial comum em relação à China, com uma intenção de promover produtos brasileiros e argentinos também de maneira conjunta.

Esse acontecimento mostra, em grande medida, a preocupação dos setores industriais de ambos os países frente à impossibilidade de competir com os produtos chineses. Pouco teve que se esperar para uma resposta chinesa. No dia 3 de abril de 2010, a decisão da RPC de frear o ingresso de óleo de soja de origem argentino por razões sanitárias ${ }^{15}$ criou uma rispidez nas relações bilaterais (MALESTAR OFICIAL CON CHINA, 2010; EXIGEN SOLUCIONES A LA CRISE, 2010) que estava amadurecendo, não só por meras razões conjunturais do comércio internacional, mas também por razões estruturais, que também se remontam as trajetórias históricas do desenvolvimento da Argentina e do Brasil. Ambos os países, mas principalmente o Brasil, conseguiram formar setores industriais de peso, cujos interesses refletem-se na estrutura do Estado e na elaboração das políticas públicas e, portanto, na sua política externa. A partir de 2008 e 2009, no meio da crise econômica, o conflito de interesses latente saltou à luz (OLIVEIRA \& PAUL, 2009; RODRÍGUEZ, 2009; MOURA E SOUZA, 2010).

\footnotetext{
15 O óleo de soja de origem argentina teria uma proporção de resíduo de solvente além da permitida por novas normas técnicas de qualidade incorporadas pela RPC (DELLATORRE, 2010).
}

Embora, o comércio com a RPC seja uma nova opção para os países do Sul, o CP apresenta impactos diferenciados na sub-região e desdobramentos geopolíticos da maior importância e complexidade para a integração sul-americana. Como foi destacado, trata-se de uma relação fundamentalmente, mas não exclusivamente, econômica, na qual a China precisa de estabilidade política regional e de bom relacionamento com os EUA; o vínculo comercial crescente está baseado, sobretudo, em uma relação de complementaridade com perigo de cristalizar-se em uma especialização estilo centro-periferia; e no âmbito dessa relação, a RPC está implementando, em vários casos, programas de ajuda e de cooperação - além dos investimentos em infraestrutura que foram citados -, não impondo condicionalidades políticas específicas de curto prazo. Esse conjunto de políticas conforma o padrão de relacionamento que denominamos de Consenso do Pacífico e que se apresenta como uma variável de extrema relevância para compreender os futuros desdobramentos do processo de integração sul-americana. Uma das conseqüências mais destacadas talvez seja o reforço dos princípios do regionalismo aberto ${ }^{16}$ na sub-região, o que, em grande medida, conflita com a estratégia de política externa brasileira implementada na última década e aprofundada, sobretudo, durante o governo de Luiz Inácio Lula da Silva.

O indício mais destacado do ressurgimento do regionalismo aberto ${ }^{17}$ na América Latina nasceu da iniciativa do Peru, um dos três países que assi-

16 O “regionalismo aberto” é um modelo de integração regional dominante na década de 1990, preconizado especialmente pela Cepal. A integração sob essa perspectiva é concebida como "um cimento que favoreça uma economia internacional mais aberta e transparente, em vez de converter-se em um obstáculo que o impeça, limitando assim as opções de alcance dos países da América Latina e do Caribe. Isso significa que os acordos de integração deveriam tender a eliminar as barreiras aplicáveis à maior parte do comércio de bens e serviços entre os signatários no marco de suas políticas de liberalização comercial frente a terceiros, ao tempo que se favorece a adesão de novos membros aos acordos” (CEPAL, 1994).

17 O regionalismo aberto tem como princípio basilar criar um espaço comercial em uma região específica em consonância com o regime multilateral de comércio e que permita aos países membros assinarem acordos de livre-comércio de maneira individual, modelo que o Chile e o Peru já vêm aplicando. 
naram um TLC com a RPC (PERU, 2010). O "Foro del Arco del Pacífico Latinoamericano" é um acordo que aglutina estados da América do Sul, América Central e o México ${ }^{18}$ com claros interesses no estímulo do comércio via oceano pacífico, sem a intenção de ir além de um tratado de livre comércio ${ }^{19}$. Briceño Ruiz (2010) destaca que o Foro do Arco do Pacífico Latino-americano (Fapla) surgiu não só para legitimar a política externa comercial de países como Peru ou Chile, mas também como uma resposta às debilidades da Comunidade Andina de Nações (CAN) e como uma maneira de contrapor-se à proposta "antisistêmica” da Alternativa Bolivariana para as Américas (ALBA) ${ }^{20}$ liderada por Hugo Chávez. Contudo, acreditamos que o Fapla é uma resposta regional às transformações econômicas globais e ao papel cada vez mais importante da China e do Sudeste Asiático no comércio e nos investimen-

18 Peru, Colômbia, Costa Rica, Chile, Equador, El Salvador, Honduras, Nicarágua e México foram os signatários do acordo.

19 "La iniciativa del ARCO-FAPLA - se encuentra em proceso de consolidación como un espacio de diálogo político y concertación en torno a temas de caráter econômico y comercial. Los países participantes han reconocido afinidades no solo por compartir la Cuenca Latinoamericana del Pacífico, sino también por La necesidad compartida de fortalecer los vínculos y ampliar La cooperación con los países de Ásia Pacífico”. Ver o acordo inicial em Foro Del Arco del Pacífico Latinoamericano (2008).

20 Além da Venezuela, também Bolívia, Cuba e Nicarágua compõem o bloco. tos na região ${ }^{21}$. Essas mudanças abriram mais ainda o leque de opções desses países, fortalecendo ainda mais os princípios do regionalismo aberto e colocando mais um desafio para a liderança brasileira nos projetos de integração na América do Sul, seja o Mercosul ou a Unasul.

Concluindo, o projeto da globalização não poderá ser escrito só com as regras de Washington, simplesmente porque a economia global está conformando-se como um sistema multipolar, no qual a RPC tem o papel mais destacado dentre as novas potências regionais. A crise econômica de 2008 foi o efeito catalisador para a China ocupar espaços cada vez mais importantes nas instituições internacionais e para a sua expansão de investimentos nas mais diversas regiões do planeta. A RPC não se apresenta como uma potência revisionista ou um poder contra-hegemônico no sistema econômico mundial. O gigante asiático pretende acelerar a integração da economia global, mas ao seu modo e a seu ritmo. Isso implica desenvolver e aumentar as relações comerciais e financeiras com outras regiões, o que, por sua vez, está conformando outra geografia da economia política global. Isso significa que, nessa nova configuração, o papel da RPC será o centro - não da economia global como uma totalidade onde a preeminência dos EUA, embora diminuída, permanece - de uma rede global de conexões comerciais e financeiras que abrange diversas regiões, entre as quais a América do Sul é uma delas.

21 A saída da Venezuela da CAN em 2006 acelerou ainda mais a crise desse bloco.

Javier Vadell (javier.vadell@pucminas.br) é Doutor em Ciências Sociais pela Universidade Estadual de Campinas (Unicamp) e Professor de Relações Internacionais da Pontifícia Universidade Católica de Minas Gerais (PUC-MG).

\section{REFERÊNCIAS BIBLIOGRÁFICAS}

ALDEN, C. 2007. China in Africa. London: Zed.

ARRIGHI, G. 2008. Adam Smith em Pequim. São Paulo: Boitempo.

ARSON, C; MOHR, M. \& ROETT, R. (eds.). 2008. Enter The Dragon? China's Presence in Latin America. Washington (DC): Woodrow Wilson. Disponível em: http:// www.wilsoncenter.org/sites/default/files/
EnterDragonFinal.pdf. Acesso em: 26.set.2011.

BÁRCENA, A. \& ROSALES, O. 2010. La República Popular de China y América Latina y el Caribe: hacia una relación estratégica. Santiago: Cepal. Disponível em: http:// www.eclac.org/publicaciones/xml/2/39082/ RP_China_America_Latina_el_Caribe_una_relacion_ estrategica.pdf. Acesso em: 26.set.2011. 
BLÁZQUEZ-LIDOY, J.; RODRÍGUEZ, J. \& SANTISO, J. 2006. Angel o demonio? Los efectos del Comércio chino en los países de América Latina. Revista de la Cepal, Santiago, n. 90, p. 17-43, dic. Disponível em: http:/ /www.eclac.cl/publicaciones/xml/6/27636/ LCG2323eSantiso.pdf. Acesso em: 26.set.2011.

BRICEÑO RUIZ, J. 2010. La Iniciativa del Arco del Pacífico Latinoamericano: un nuevo actor en el escenario de la Integración Regional. Nueva Sociedad, n. 228, p. 44-59, jul.-ago. Disponível em: http://www.nuso.org/upload/ articulos/3705_1.pdf. Acesso em: 26.set.2011.

CORNEJO, R. \& NAVARRO GARCÍA, A. 2010. China y América Latina: recursos, mercados y poder global. Nueva Sociedad, n. 228, p. 79-99. jul.-ago. Disponível em: http:// www.nuso.org/upload/articulos/3707_1.pdf. Acesso em: 26.set.2011.

DELLATORRE, R. 2010. La soja sigue dando sorpresas. Página/12, Buenos Aires, 4.mar. Disponível em: http://www.pagina12.com.ar/ diario/economia/2-143242-2010-04-04.html. Acesso em: 26.set.2011.

DIRLIK, A. 2007. Beijing Consensus: Beijing 'Gongshi'. Who Recognizes Whom and to What End? Globalization and Autonomy, Position Papers. Disponível em: http:// www.globalautonomy.ca/global1/servlet/ Position2pdf?fn=PP_Dirlik_BeijingConsensus. Acesso em: 11.nov.2008.

DOMÍNGUEZ, J. I.; CATALINAC, A.; CESARIN, S.; CORRALES, J.; GOLOB, S. R.; KENNEDY, A.; LIEBMAN, A.; MUSACCHIO-FARIAS, M.; RESENDESANTOS, J.; K.; RUSSEL, R. \& RYU, Y. 2006. China's Relations with Latin America: Shared Gains, Asymmetric Hopes. InterAmerican Dialogue, Working Paper, June. Disponível em: http://www.wcfia.harvard.edu/ sites/default/files/Dominguez_Chinas.pdf. Acesso em: 22/11/2008.

DYER, G.; ANDERLINI, J. \& SENDER, H. 2010. China's Lending Hits New Heights. Financial Times, London, 17.Jan. Disponível em: http://www.ft.com/intl/cms/s/0/488c60f42281-11e0-b6a2-00144feab49a.html. Acesso em: 26.set.2011.
EDNA, S. 2010. Brasil e Argentina se unem contra produtos chineses. O Estado de S. Paulo, 26.mar. Disponível em: http://www.estadao. com.br/noticias/impresso,brasil-e-argentinase-unem-contra-produtos-chineses, 529317,0.htm. Acesso em: 26.set.2011.

ELLIS, E. R. 2005. U.S. Nacional Security Implications of Chinese Involvement in Latin America. Carlisle: Strategic Studies. Disponível em: http://www.strategicstudiesinstitute. army.mil/pdffiles/pub606.pdf. Acesso em: 26.set.2011.

2006. El Nuevo Romance Chino con América Latina: Comprendiendo la Dinámica y las Implicaciones Regionales. Air \& Space Power Journal, v. 18, n. 3, Fall. Disponível em: http:/ /www.au.af.mil/au/cadre/aspj/apjinternational/ apj-s/2006/3tri06/ellis.html. Acesso em: 26.set.2011.

2009. China in Latin America: the Whats and Wherefores. Boulder: Lynne Rienner.

GALLAGHER, K. 2010. China and the Future of Latin American Industrialization. Issues in Brief, Boston, p. 1-8, Oct. Disponível em: http:// www.bu.edu/pardee/files/2010/10/18-IIB.pdf. Acesso em: 23/10/2010.

GALLAGHER, K. P. \& PORZECANSKI, R. 2009. China and the Latin America Commodities Boom: A Critical Assessment. Political Economy Research Institute, Amherst, n. 192, p. 1-27, Feb. Disponível em: http://www.peri.umass.edu/fileadmin/pdf/ working_papers/working_papers_151-200/ WP192.pdf Acesso em: 18/04/2009.

2010. The Dragon in the Room: China and the Future of Latin American Industrialization. Stanford: Stanford University.

HARVEY, D. 2008. Neoliberalismo. História e implicações. São Paulo: Loyola.

HOOK, L. 2010. Sinopec to put \$7.1bn in Repsol Brasil. Finantial Times, London, 1.Oct. Disponível em: http://www.ft.com/cms/s/0/7bf9a8aac d 3 3-11df - ab 20-00144f e ab 49 a . html\#axzz1ZyoVk8fA. Acesso em: 26.set.2011.

HUNG, H. F. 2009. Introduction: The Three Transformation of Global Capitalism. In: HUNG, H.-F. (ed.). China and the Transforma-tion of Global Capitalism. Baltimore: The John Hopkins University. 
LEO, S. 2010. Brasil e Argentina dizem que superaram conflitos e preparam missão à China. Valor Econômico, São Paulo, 26.mar. Disponível em: http://www.softcomex.com.br/noticias/index.php?option=com_k2\&view $=\mathrm{i}$ tem\&id=457:brasil-e-argentina-dizem-que-superaram-conflitos-e-preparam-miss\%C3\% A3o\%C3\%A0-china. Acesso em: 26,mar.2010.

JENKINS, R. 2009. América Latina frente al dragón chino: oportunidades, retos $\mathrm{y}$ respuestas. Norwich: University of East Anglia.

JENKINS, R.; DUSSEL PETERS, E. \& MESQUITA MOREIRA, M. 2008. The Impact of China on Latin America and the Caribbean. World Development, Kidlington, v. 36, n. 2, p. 235253. Disponível em: http://www.bristol.ac.uk/ ceas/chinaintheworld/readings/Jenkins\%20 MOREIRA\%20and\%20Peters.pdf. Acesso em: 26.set.2011.

KENNEDY, S. 2010. The Myth of the Beijing Consensus. Journal of Contemporary China, New York, v. 19, n. 65, p. 461-477, June. Disponível em: http://chinatrack.typepad.com/files/kennedy-myth-pub-june-10.pdf. Acesso em: 26.set.2011.

LAMAS, B. 2007. China: anjo e demônio para a América do Sul. Observador On-Line, v. 2, n. 5, p. 2-18, abr.

LANDAU, S. 2005. Chinese Influence on the Rise in Latin America. Foreign Policy in Focus, Washington (DC), 30.June. Disponível em: http://globalpolitician.com/2939-china-latinamerica. Acesso em: 26.set.2011.

MOURA E SOUZA, M. 2010. Acordo Comercial Peru-China gera atrito com Brasil. Valor Econômico, São Paulo, 3.mar. Disponível em: h t t p: / / w w w. in te log. net/site / default.asp?TroncoID $=907492 \&$ SecaoID $=$ 508074\&SubsecaoID $=619181 \&$ Template $=. . /$ artigosnoticias/user_exibir.asp\&ID= 137149\&Titulo=Acordo\%20comercial\%20 Peru-China\%20gera\%20atrito\%20com\% 20Brasil. Acesso em: 26.set.2011.

MORAES, R. 2001. Neoliberalismo. De onde vem, para onve vai? São Paulo: SENAC.

OLIVEIRA, E. \& PAUL, G. 2009. China ganha espaço do Brasil na América Latina. O Globo, Rio de Janeiro, 2.ago.
RAMO, J. C. 2004. The Beijing Consensus: Notes on the New Physics of Chinese Power. London: Foreign Policy. Disponível em: http:/ /www.ids-uva.nl/wordpress/wp-content/ uploads/2011/07/10_Cooper.pdf. Acesso em: 26.set.2011

RATLIFF, W. 2009. In Search of a Balanced Relationship: China, Latin America and United States. Asian Politics \& Policy, Malden, v. 1, n. 1, p. 1-30, Jan. Disponível em: http:// onlinelibrary.wiley.com/doi/10.1111/j.19430787.2009.01100.x/pdf. Acesso em: 26.set.2011.

RODRÍGUEZ, E. 2009. Brasil faz obras nos vizinhos temendo China. Folha de S. Paulo, 30.set. Disponível em: http://revistae coturismo.com.br/ turismo-sustentabilidade/brasil-faz-obras-nosvizinhos-temendo-china/. Acesso em: 26.set.2011.

ROETT, R. \& PAZ, G. 2008. China's Expansion into the Western Hemisphere: Implications for Latin America and the United States. Washington (DC): Brookings.

SANTISO, J. (org.). 2009. La mano visible de China en América Latina. Paris: OCDE.

SIMÃO, E. 2010. Brasil e Argentina se unem contra produtos chineses. O Estado de S. Paulo, 26.mar. Disponível em: http://www.estadao .com.br/estadaodehoje/20100326/not_imp 529317,0.php. Acesso em: 26.set.2011.

SCISSORS, D. 2011. China Global Investment Tracker: 2011. The Heritage Foundation, White Paper, Washington (DC), Jan. Disponível em: http://www.heritage.org/Research/ Reports/2011/01/China-Global-InvestmentTracker-2011. Acesso em: mar 032011.

SEVARES, J. 2006. ¿Cooperación Sur-Sur o Dependencia a la Vieja Usanza? América Latina en el Comércio Internacional. Nueva Sociedad, n. 207, p. 11-22, ene.-feb. Disponível em: http://www.nuso.org/upload/articulos/ 3402_1.pdf. Acesso em: 26.set.2011.

SHIXUE, J. 2008. Three Factors in Recent Development of Sino-Latin American Relations. In: ARSON, C.; MOHR, M. \& ROETT, R. (eds.). Enter The Dragon? China's Presence in Latin America. Washington (DC): Woodrow Wilson Center: Woodrow Wilson. 
TAYLOR, I. 2006. China and Africa: Engagement and Compromise. New York: Routledge.

2009. China's New Rol in Africa. Boulder: Lynne Rienner.

TOKATLIAN, J. G. 2008. A View from Latin America. In: ROETT, R. \& PAZ, G. (eds.). China's Expansion into the Western Hemisphere: Implications for Latin America and the United States. Washington (DC): Brookings.

TORTORIELLO, A. M. 2004. Brasil aceita China como economia de Mercado. BBC Brasil, São Paulo, 12.nov. Disponível em: http:// www.bbc.co.uk/portuguese/reporterbbc/ story/2004/11/041112_jintao.shtml. Acesso em: $13 / 11 / 2004$
VADELL, J A. 2002. O pensamento social de Friedrich von Hayek e a teoria política contemporânea. Campinas: UNICAMP.

2007. As implicações políticas da Relação China-América do Sul no século XXI. Cena Internacional, Brasília, v. 9, n. 2, p. 194-214.

2010. A crescente presença da China na América do Sul: rumo a um Consenso de Pequim? In: VADELL, J. \& CAMPOS, T. (orgs.). Os novos rumos do regionalismo e as alternativas políticas na América do Sul. Belo Horizonte: PUC-MG.

WILLIAMSON, J. 1990. What Washington Means by Policy Reform. In: WILLIAMSON, J. (ed.). Latin American Adjustment: How Much Has Happened? Washington (DC): Institute for International Economics.

\section{OUTRAS FONTES}

BRASIL. MINISTÉRIO DAS RELAÇÕES EXTERIORES. 2003. Consenso de Buenos Aires. Disponível em: http://www2.mre.gov.br/dai/ b_argt_385_5167.htm. Acesso em: 26.set.2011.

Brasil e Argentina apostam na integração produtiva para superar problemas. 2010. Folha de S. Paulo, 26.mar. Disponível em: http:// www1.folha.uol.com.br/folha/dinheiro/ ult91u712637.shtml. Acesso em: 26.set.2011.

CEPAL. 1994. El Regionalismo abierto en América Latina y el Caribe: la integración económica al servicio de la transformación productiva con equidad. Libros de la Cepal, Santiago, n. 39, ene. Disponível em: http://www.eclac.org/ publicaciones/xml/7/4377/lcg1801e.htm. Acesso em: 26.set.2011.

China pone a disposición de la Argentina US\$ 10.200 millones. 2009. La Nación, Buenos Aires, 31.mar. Disponível em: http:// www.lanacion.com.ar/1113735-china-pone-adisposicion-de-la-argentina-us-10200-millones. Acesso em: 26.set.2011.

DIARIO OFICIAL DE LA REPUBLICA DE CHILE. 2006. Normas Generales. Disponível em: http://www.sofofa.cl/comex/normas/ china/DO_26-09-2006_TLC_Chile-China.pdf. Acesso em: 26.set.2011.
Exigen soluciones a la crisis comercial con China por la importación de soja. 2010. La Nación, Buenos Aires, 4.abr. Disponível em: http:// www.lanacion.com.ar/1250576-exigen-soluciones-a-la-crisis-comercial-con-china-por-laimportacion-de-soja. Acesso em: 26.set.2011.

Firman un acuerdo con China para fortalecer las reservas. 2009. Clarín, Buenos Aires, 31.mar. Disponível em: http://edant.clarin.com/diario/ 2009/03/31/elpais/p-01888196.htm. Acesso em: 26.set.2011.

FORO DEL ARCO DEL PACÍFICO LATINOAMERICANO. 2008. Lineamientos generales del Foro del Arco del Pacífico Latinoamericano. Documento apresentado na $4^{\text {a }}$ Reunión Ministerial do Foro del Arco del Pacífico Latinoamericano, Santiago. Disponível em: http://www.arcodelpacifico.org/ upload/declaracion_santiago.pdf. Acesso em: 26.set.2011.

Malestar oficial con China por la crisis de la soja: citan al embajador. Clarin, Buenos Aires, 3.abr. Disponível em: http://edant.clarin.com/diario/ 2010/04/03/elpais/p-02172797.htm. Acesso em: 26.set.2011.

PEOPLE'S REPUBLIC OF CHINA. 2011. The Central People's Government of the People's 
Republic of China. Sítio de internet. Disponível em: http://english.gov.cn/. Acesso em: 27.set.2011.

PERU. MINCETUR. 2010. Tratado de Libre Comercio Perú-China. Disponível em: http:// www.capechi.org.pe/pdfs/Informes Finales_TLC_Peru-China.pdf. Acesso em: 26.set.2011.
Ratifican una inversión china para explotar Gás en El Sur. 2010. La Nación, Buenos Aires, 19.nov. Disponível em: http://www.lanacion. com.ar/nota.asp?nota_id=1326162. Acesso em: 26.set.2011.

Too Much Consensus. 2004. Foreign Policy, Washington (DC), 1.Sep. Disponível em: http:// www.foreignpolicy.com/articles/2004/09/01/ too_much_consensus. Acesso em: 26.set.2011. 


\section{CHINA IN SOUTH AMERICA AND THE GEOPOLITICAL IMPLICATIONS OF THE PACIFIC CONSENSUS}

\section{Javier Vadell}

This article analyzes the political implications of the increasing interdependence of the People's Republic of China (PRC) and South American countries. We present data on PRC investment and trade in the region and highlight several points of diplomatic progress in terms of bi-lateral cooperation for the $21^{\text {st }}$ century. Our starting point is the issue of whether we face a relationship that could constitute a new form of South-South cooperation or whether it is more representative of the typical North-South pattern or system - albeit one with its own peculiarities. We refer to this relationship pattern as Pacific Consensus (PC). Although short term, the China factor may stimulate growth in the region, it also has different implications for the development of countries with an important industrial sector - such as Brazil and Argentina - and those that do not - such as Chile and Peru which have all signed free trade agreements with the Asiatic giant. We conclude with some considerations regarding the consequences that the PC has in terms of Latin American integration.

KEYWORDS: China; South America; Integration, Pacific Consensus. 


\section{LA CHINE EN AMÉRIQUE DU SUD ET LES IMPLICATIONS GÉOPOLITIQUES DU CONSENSUS DU PACIFIQUE}

\section{Javier Vadell}

L’article analyse les implications politiques de la croissante interdépendance économique entre la République Populaire de la Chine (RPC) et les pays de l'Amérique du Sud. Des données sur le commerce et l'investissement de la RPC dans la sous-région sont présentées, et les progrès diplomatiques en matière de coopération bilatéral dans le XXI siècle sont soulignés. Premièrement, nous cherchons à savoir si nous sommes devant un modèle de relation qui pourrait constituer une relation renouvelée de coopération Sud-Sud, ou bien, un nouveau type de relation Nord-Sud. Selon notre hypothèse, l'évolution et la dynamique de cette relation ressemblent plutôt à un système ou à un modèle Nord-Sud aves des caractéristiques bien particulières. Nous appelons ce modèle de relation, le Consensus du Pacifique (CP). Malgré que le facteur Chine stimule, à court terme, la croissance de la sous-région, le CP a des implications différenciées pour le développement des pays qui détiennent un secteur industriel important - ex. Le Brésil et l’Argentine - et ceux qui n'en ont pas - ex. le Chili et le Pérou, qui ont même signé des traités de libre commerce avec le géant asiatique. L'article est conclu avec quelques observations sur les conséquences du CP dans le processus d'intégration sud-américaine.

MOTS-CLÉS: la Chine ; l’Amérique du Sud ; l’intégration ; le Consensus du Pacifique. 